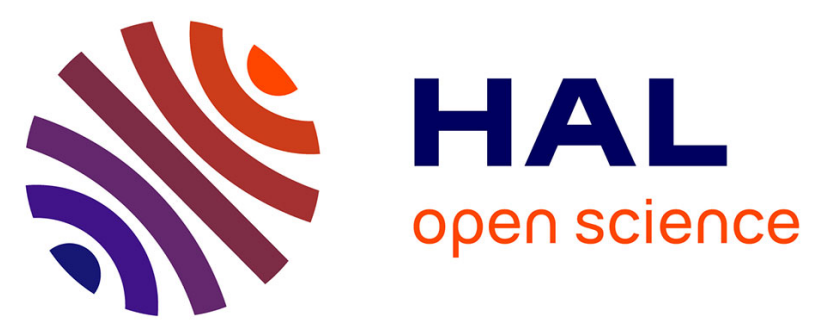

\title{
From experimental variability to the sorption related retention parameters necessary for performance assessment models for nuclear waste disposal systems: The example of $\mathrm{Pb}$ adsorption on clay minerals
}

Esra Orucoglu, Christophe Tournassat, Jean-Charles Robinet, Benoît Made, Mélanie Lundy

\section{To cite this version:}

Esra Orucoglu, Christophe Tournassat, Jean-Charles Robinet, Benoît Made, Mélanie Lundy. From experimental variability to the sorption related retention parameters necessary for performance assessment models for nuclear waste disposal systems: The example of $\mathrm{Pb}$ adsorption on clay minerals. Applied Clay Science, 2018, 163, pp.20 - 32. 10.1016/j.clay.2018.07.003 . insu-01857042

\section{HAL Id: insu-01857042 \\ https://hal-insu.archives-ouvertes.fr/insu-01857042}

Submitted on 30 Sep 2020

HAL is a multi-disciplinary open access archive for the deposit and dissemination of scientific research documents, whether they are published or not. The documents may come from teaching and research institutions in France or abroad, or from public or private research centers.
L'archive ouverte pluridisciplinaire HAL, est destinée au dépôt et à la diffusion de documents scientifiques de niveau recherche, publiés ou non, émanant des établissements d'enseignement et de recherche français ou étrangers, des laboratoires publics ou privés. 
1 From experimental variability to the sorption related retention parameters

2 necessary for performance assessment models for nuclear waste disposal systems: the example of $\mathbf{P b}$ adsorption on clay minerals.

Orucoglu Esra ${ }^{1,2^{*}}$, Tournassat Christophe ${ }^{1,2,3^{*}}$, Robinet Jean-Charles ${ }^{4}$, Madé Benoît ${ }^{4}$, Lundy Mélanie $^{4}$

${ }^{1}$ Institut des Sciences de la Terre d'Orléans, UMR 7327 Université d'Orléans-CNRS/INSU-BRGM, 45071 Orléans, France

${ }^{2}$ BRGM, 3 avenue Claude Guillemin, 45060 Orléans, France

${ }^{3}$ Earth and Environmental Sciences Area, Lawrence Berkeley National Laboratory, Berkeley, CA 94720, USA

${ }^{4}$ Andra, 1 - 7 rue Jean Monnet, 92298 Châtenay-Malabry, France

*Corresponding authors: esra.orucoglu@cnrs-orleans.fr, c.tournassat@brgm.fr

\section{Abstract}

Surface complexation models (SCMs) have been developed in the last decades to describe metal ion sorption to clay minerals and especially to montmorillonite. In principle, these models can provide relevant information about sorption of radionuclides to be used in performance assessment (PA) of radioactive waste disposal systems. However, these SCMs have been developed in parallel with the acquisition of distinct adsorption datasets, which are not always consistent with each other. The objective of this study was to compare new experimental adsorption results with literature data to understand these discrepancies and to propose a SCM approach that could be amenable to determine sorption related retention parameters necessary for PA calculations. This study focused on lead ( $\mathrm{Pb}$ ) adsorption on montmorillonite, illite and in a natural clay (Callovo Oxfordian) as case studies of a strongly sorbing radionuclide that undergoes a range of retention processes depending on the chemical conditions. The experiments showed that many experimental artifacts lead to misinterpretations of the processes underlying the measured retention values. These include $\mathrm{Pb}$ precipitation in the presence of carbonate in solution. The determination of SCM parameters to provide sorption related information for PA of clay minerals should rely on preliminary building of an adequate adsorption database, where adequate means that all experimental conditions are met to quantify surface complexation only. 


\section{Introduction}

In recent years, the scientific community has seen a remarkable surge of interest in the properties and behavior of clays as they apply to a variety of natural and engineered settings. Clay materials are known as an important part of the multi-barrier system for nuclear waste storage around the world, and their performance must be demonstrated on the time scale of hundreds to millions of years (Altmann 2008, Busch et al. 2008, Chapman and Hooper 2012, Armitage et al. 2013, Neuzil 2013). In these applications, the low hydraulic conductivity of the clay mineral-rich geological formations or of the engineered clay barriers provides at least part of the basis for isolating radionuclide contaminants (RN). Clay minerals have high adsorption capacity for a large range of radionuclides (Bradbury and Baeyens 2005a). The strong adsorption and resulting retardation of many contaminants by clay minerals make them ideal for use in natural or engineered barrier systems, particularly where there is a desire to improve confidence in the safety case beyond the reliance on slower transport rates alone (Altmann et al. 2012, Gaboreau et al. 2012, Borisover and Davis 2015, Grangeon et al. 2015). Because contaminant mobility in clay materials is mainly driven by diffusion and adsorption processes, a typical (simplified) scheme for estimating radionuclide release relies on knowing three parameters. The first is the effective diffusion coefficient (De), which quantifies the transport of each radionuclide across the barriers. The second is the distribution ratio of the radionuclide between the solution and the solid phases/surface $\left(R_{D}\right.$ or $K_{D}$ if the retention is reversible), which quantifies the accumulation on the solid and the retardation of the radionuclide as it migrates from the repository across the barriers. The third is the solubility, which controls the maximum concentration in solution of the radionuclide of interest according to the geochemical conditions. These parameters are site specific, so to determine them specific data acquisition programs are needed. However, there is a fundamental difference between solubility and $K_{D}$ values. Solubility values are usually obtained from the interpretation of experimental data with thermodynamic laws, which can be considered to be always valid, so solubility values can be applied to site-specific conditions, if environmental conditions such as temperature, pressure, and pore water composition are known, and with the assumption of precipitation/dissolution at thermodynamic equilibrium. Conversely, $K_{D}$ values are directly measured in the presence of experimental conditions that are supposed to be representative of the in situ environmental conditions. As a direct consequence, knowledge about $K_{D}$ values cannot be easily transferred from one site condition to another. For decades, quasi-thermodynamic models have been developed to predict the adsorption properties of many natural materials including clay minerals, oxides and organic matter. These models, grouped here under the term surface complexation models (SCM), aim to predict adsorption processes in a wide range of environmental conditions (Sposito 1984, Davis and Kent 1990, Dzombak and Morel 1990, Hiemstra and Van Riemsdijk 1996, Davis et al. 1998). If complete enough, they can be transferred from one site condition to another, providing that the dominant mechanisms have been identified and adequately quantified. In principle, these models could be used in performance assessment (PA) with calculations carried out with reactive transport codes. In practice, this is seldom the case, but recently, a hybrid approach, named "Smart $\mathrm{K}_{\mathrm{D}}$ ", which takes advantage of SCM flexibility with regards to changes in environmental conditions together with simplified models more amenable to PA calculations, 
has been advanced to include more flexibility, predictability and transferability in these PA calculations (Richter et al. 2009, Stockmann et al. 2012, Druteikien et al. 2017). Near-field conditions will change over time following local perturbations induced by the presence of the waste repository. As an example, heat release from a radioactive waste package will temporarily increase the temperature that will itself influence the adsorption properties of clay minerals because of at least two processes. First, the affinity of the clay surfaces for a given RN is dependent on temperature (Tertre et al., 2005). Second, a temperature change influences the geochemical characteristics of the porewater, especially the $\mathrm{pH}$, changing the distribution of species (speciation) in solution for the elements of interest (Gailhanou et al. 2017). So estimating SCM parameters and their associated uncertainties in as wide a range of conditions as possible is a key aspect in developing these PA approaches.

SCM parameters must be calibrated with experimental data in well-defined and wellcontrolled conditions. This is necessary in order to extrapolate the results in a wide range of conditions and to apply them to natural materials using a component additivity (CA) approach (Davis et al. 2004, Chen et al. 2014a, 2014b). The choice of the SCM is also important. A range of SCM that is applied to clay minerals and especially to montmorillonite have been developed and described in the literature (Zachara and Smith 1994, Bradbury and Baeyens 1997, Ikhsan et al. 2005, Gu and Evans 2007, Marcussen et al. 2009, Tertre et al. 2009, Gu et al. 2010, Akafia et al. 2011). These SCMs were developed in parallel with the acquisition of distinct adsorption datasets, which are not always consistent with each other (Tournassat et al. 2013). Several sources of discrepancies explain these inconsistencies, including differences in the properties of the clay materials (for example, natural variability in chemistry and size distribution, and preparation prior to experiments including sedimentation techniques and chemical treatments to remove mineral and organic impurities), differences in experimental procedures (order of reagent addition), and experimental artifacts. So the objective of this study was to compare new experimental adsorption results with literature data in order to understand these discrepancies and to propose a SCM approach that could be amenable to the determine sorption related retention parameters necessary for PA calculations. This study was focused on $\mathrm{Pb}$ adsorption as a case study of a strongly sorbing radionuclide on montmorillonite, illite and a natural clay mineral (Callovian-Oxfordian) (COx) that undergoes a range of retention processes as a function of chemical conditions.

\section{Material and Methods}

\subsection{Overview of Experiments}

Batch adsorption experiments were conducted with three different reference clay minerals, namely two montmorillonites (MX-80 and Kunipia-P) and one illite, and with a natural clay mineral assemblage present in $\mathrm{COx}$ claystone, in order to quantify the main adsorption mechanisms of $\mathrm{Pb}$ on clays. To clarify the effect of each of these mechanisms, various adsorption experiments were designed spanning a range of different solid/liquid ratio $\left(\mathrm{R}_{\mathrm{SL}}\right.$ in $\left.\mathrm{g} \cdot \mathrm{L}^{-1}\right)$, ionic strength $(\mathrm{NaCl}$ as a background electrolyte), $\mathrm{pH}$, temperature, and initial $\mathrm{Pb}$ concentrations (Table 1). 
121 Table 1. Summary of experimental conditions used with three different reference clays 122 (purified MX-80, Kunipia and illite and one clay fraction of COx claystone).

\begin{tabular}{lllll}
\hline $\begin{array}{c}\text { Initial Pb } \\
\text { concentration } \\
(\mu \mathrm{M})\end{array}$ & $\mathrm{R}_{\mathrm{SL}}\left(\mathrm{g} \cdot \mathrm{L}^{-1}\right)$ & $\begin{array}{l}\mathrm{NaCl} \\
\text { concentration } \\
(\mathrm{M})\end{array}$ & $\mathrm{pH}$ range & $\mathrm{T}\left({ }^{\circ} \mathrm{C}\right)$ \\
\hline 1 & 1 & 0.1 & $3-9$ & $20^{*}$ \\
10 & 1 & 0.1 & $3-9$ & $20^{*}$ \\
50 & 1 & 0.1 & $3-9$ & $20^{*}$ \\
1 & 0.5 & 0.025 & $3-9$ & $20^{*}$ \\
1 & 1 & 0.1 & $3-7$ & 67 \\
\hline
\end{tabular}

123

124

125

126

127

128

129

130

131

132

133

134

135

136

137

138

139

140

141

142

143

144

145

146

147

148

149

150

151

152

153

154

* Room temperature

\subsection{Chemicals}

All chemicals used in the experiments were analytical grade: $\mathrm{Pb}\left(\mathrm{NO}_{3}\right)_{2}$ (Prolab R.P. Normapur, > 99.5\%), $\mathrm{NaCl}$ (Merck, 99.6\%), 30\% HCl (Merck, Suprapur), NaOH pellets (Merck, > 99\%), 65\% $\mathrm{HNO}_{3}$ (VWR Prolabo, 69.4\% for cleaning, and Merck, Suprapur for AAS measurements), acetic acid $\left(\mathrm{C}_{2} \mathrm{H}_{4} \mathrm{O}_{2}\right.$, VWR Prolab, 96\%), citric acid $\left(\mathrm{C}_{6} \mathrm{H}_{8} \mathrm{O}_{7} \cdot \mathrm{H}_{2} \mathrm{O}\right.$, Carlo Erbar, >99.8\%), sodium bicarbonate $\left(\mathrm{NaHCO}_{3}\right.$, ACS Amresco), 30\% $\mathrm{H}_{2} \mathrm{O}_{2}$ (Merck), sodium dithionite $\left(\mathrm{Na}_{2} \mathrm{~S}_{2} \mathrm{O}_{4}\right)$, MES $\left(\mathrm{C}_{6} \mathrm{H}_{13} \mathrm{NO}_{4} \mathrm{~S}\right.$, Sigma Aldrich, $\left.>99 \%\right)$, MOPS $\left(\mathrm{C}_{7} \mathrm{H}_{15} \mathrm{NO}_{4} \mathrm{~S}\right.$, Sigma Aldrich, >99.5\%), tri sodium citrate dehydrate $\left(\mathrm{C}_{6} \mathrm{H}_{5} \mathrm{Na}_{3} \mathrm{O}_{7} .2 \mathrm{H}_{2} \mathrm{O}\right.$, Fluka, 99.99\%). Milli-Q $18 \mathrm{M} \Omega$ water was used in all solution preparation, clay suspension and clay purification processes.

\subsection{Solution Preparation}

$\mathrm{NaCl}$ stock solutions $(0.1 \mathrm{M}$ and $0.025 \mathrm{M})$ were prepared from crystalline $\mathrm{NaCl}$. $\mathrm{HCl}$ stock solution $(1 \mathrm{mM})$ and $\mathrm{NaOH}$ stock solution $(1 \mathrm{mM})$ were prepared from $30 \% \mathrm{HCl}$ acid solution and $\mathrm{NaOH}$ pellets, respectively. Two $1 \mathrm{mM} \mathrm{Pb}$ stock solutions at two different ionic strength were prepared by dissolving crystalline $\mathrm{Pb}\left(\mathrm{NO}_{3}\right)_{2}$ in a $1 \mathrm{mM} \mathrm{HCl} / 0.1 \mathrm{M} \mathrm{NaCl}$ solution and in a $1 \mathrm{mM} \mathrm{HCl}$ solution. For experiments conducted with low $\mathrm{Pb}$ concentrations, 10 and $100 \mu \mathrm{M}$ stock solutions were prepared by diluting these solutions in a $1 \mathrm{mM} \mathrm{HCl} / 0.1 \mathrm{M} \mathrm{NaCl}$ solution and in a $1 \mathrm{mM} \mathrm{HCl}$ solution. All solutions were prepared in an air atmosphere.

\subsection{Clay Material}

Clay stock dispersions with a solid / liquid ratio of $2 \mathrm{~g} \cdot \mathrm{L}^{-1}$ were prepared in a $0.1 \mathrm{M} \mathrm{NaCl}$ solution background for two montmorillonites (MX-80, and Kunipia-P), one purified illite (Illite du Puy, IdP), and the clay fraction of COx claystone. MX-80 montmorillonite was extracted from a stock of MX-80 bentonite and the clay fraction of COx claystone was obtained from the core EST 51779 (borehole OHZ6126 - depth: -476.5 m), which was drilled from the main gallery of Andra's Underground Research Laboratory sited at Bure in the Meuse district (LSMHM, France). The borehole was extracted from a formation level that is representative of the clayey unit of the COx formation; COx argillite mineralogical composition is made of clay minerals (mainly illite, mixed layer illite/smectite, kaolinite, mica and chlorite), tectosilicates (mainly quartz and feldspars) as well as carbonates (mainly calcite and dolomite) (Gaucher et al. 2004). 

were separated and purified in four stages with a procedure which was already published (Jackson 1975, Tournassat et al. 2007, 2011). A fine clay particle fraction $(<2 \mu \mathrm{m})$ was separated by sedimentation and/or centrifugation according to Stoke's law. Carbonates were removed by adding $0.1 \mathrm{M}$ acetic acid in $0.5 \mathrm{M} \mathrm{NaCl}(\mathrm{pH} \sim 5)$ and the clays were then washed with three cycles of centrifugation and re-dispersion in $0.5 \mathrm{M} \mathrm{NaCl}$ solution. The above treatment was repeated twice. Next Fe and Mn oxides were removed with DCB (dithionitecitrate-bicarbonate) treatment using dithionite diluted in $0.2 \mathrm{M}$ citrate $\left(\mathrm{C}_{6} \mathrm{H}_{8} \mathrm{O}_{7} \cdot \mathrm{H}_{2} \mathrm{O}\right), 0.5 \mathrm{M}$ $\mathrm{NaCl}, 0.1 \mathrm{M} \mathrm{NaHCO}_{3}$. The clays were then washed with three cycles of centrifugation and redispersion in $0.5 \mathrm{M} \mathrm{NaCl}$ solution. The above treatment was repeated twice. Finally, organic matter was removed with $3 \% \mathrm{H}_{2} \mathrm{O}_{2}, 0.5 \mathrm{M} \mathrm{NaCl}$ solution at $60^{\circ} \mathrm{C}$. After cooling, the clays were washed with three cycles of centrifugation and re-dispersion in $0.5 \mathrm{M} \mathrm{NaCl}$ solution. Centrifugation steps were carried out in Sigma 6K 10 Bioblock Scientific centrifuge at 13000 $\mathrm{g}$ for $30 \mathrm{~min}$ at $20^{\circ} \mathrm{C}$. The extracted clay fraction of MX-80 usually contains minor amounts (< $20 \%$ ) of quartz, cristobalite and amorphous silica impurities (Gailhanou et al. 2007, Tournassat et al. 2009). The COx clay composition was not determined in this study and was considered to be representative of the clay fraction of the claystone, i.e. approximately $50 \%$ illite and 50\% illite smectite mixed layer minerals (IS). Purified Illite du Puy (IdP) was obtained from a previous project. Its preparation procedure and characterization is described elsewhere (Gaboreau et al. 2016). The purified material was composed of illite layers (9094\%) and negligible smectite layer (4-6\%) and K-feldspar (less than 5\%). Kunipia-P is a highly purified Na-montmorillonite that contains nearly $100 \%$ montmorillonite, and that is produced by Kunimine Industries Co. Ltd. (Tachi and Yotsuji 2014).

\subsection{Adsorption Experiments}

179

180

181

182

183

184

185

186

187

188

189

190

191

192

193

194

195

196

The following procedure was used for all experimental conditions summarized in Table 1. First, Thermo Scientific ${ }^{\mathrm{TM}}$ Nalgene ${ }^{\mathrm{TM}}$ Oak Ridge High-Speed Polypropylene centrifuge tubes were acid treated $\left(\mathrm{HNO}_{3}\right)$ and washed three times with Milli-Q water before use. Then, 5 or $10 \mathrm{~mL}$ of the clay stock dispersion was equilibrated at the target ionic strength and $\mathrm{pH}$ by adding the correct amount of Milli-Q water, $0.1 \mathrm{M}$ or $0.025 \mathrm{M} \mathrm{NaCl}, 0.01 \mathrm{M}$ or $0.1 \mathrm{M} \mathrm{HCl}$ and $0.01 \mathrm{M}$ or $0.1 \mathrm{M} \mathrm{NaOH}$ stock solutions to reach a total volume of 18 or $19 \mathrm{~mL}$. In order to minimize the uncertainty on $\mathrm{R}_{\mathrm{SL}}$, the stock solution was stirred with a magnetic stirrer during its sampling. Then, 1 or $2 \mathrm{~mL}$ of acidified $\mathrm{Pb}$ stock solution $(10 \mu \mathrm{M}, 100 \mu \mathrm{M}$ or 1 $\mathrm{mM})$ was added to reach the target total $\mathrm{Pb}$ concentration $(1 \mu \mathrm{M}, 10 \mu \mathrm{M}$ or $50 \mu \mathrm{M})$. The final $\mathrm{pH}$ value was always lower than the initial $\mathrm{pH}$ after clay dispersion pre-equilibration because the $\mathrm{Pb}$ stock solutions were acid. This acid addition corresponded to approximately $20 \mu \mathrm{L} 0.1$ $\mathrm{M} \mathrm{HCl}$ per tube. At near neutral $\mathrm{pH}$ value, the $\mathrm{pH}$ value dropped by 1 to $1.5 \mathrm{pH}$ units. A preliminary kinetic experiment showed that steady-state $\mathrm{Pb}$ concentration was reached after a few hours in the conditions tested. As a result, a contact time of four days was chosen in order (i) to ensure steady state in the system, and (ii) to be in agreement with contact times of one to seven days considered in other similar studies reported in the literature ( $\mathrm{Gu}$ and Evans 2007, Gu et al. 2010, Marques Fernandes et al. 2015). Samples at room temperature were put on a horizontal shaker (Heidolph Rotamax 120) during the equilibration time. 
One of the objectives of this study was to understand the variation of clay mineral affinity for

198 lead in response to a moderate increase of temperature expected in the environment of

199 radioactive waste disposal. For this reason, experiments were conducted at $67^{\circ} \mathrm{C}$. For these 200 experiments, the $\mathrm{pH}$ was initially adjusted at room temperature with addition of $\mathrm{NaOH}$ and $201 \mathrm{HCl}$ solutions. Clay dispersions were then heated and equilibrated for seven days at $67^{\circ} \mathrm{C} . \mathrm{Pb}$ Digis the equilibrated for four at $67^{\circ} \mathrm{C}$ in a DigiPREP dry bath heater and were frequently agitated manually to re-suspend the settled clay particles. Additionally control samples were prepared for each of the experiment conditions. They were prepared with the same procedure except that the clay stock dispersion was replaced by $\mathrm{NaCl}$ stock solutions. $\mathrm{C}_{\text {init }}$ was determined from their average $\mathrm{Pb}$ concentrations at $\mathrm{pH}$ values below 6.5 .

All preparations were done in an air atmosphere except a few experiments that were carried out in a $\mathrm{N}_{2}$ atmosphere glove-box (MBraun Unilab) with stock solutions that were prepared inside the glove-box with Milli-Q that was degassed with $\mathrm{N}_{2}$-bubbling in order to purge their $\mathrm{CO}_{2}$ /bicarbonate/carbonate content. In the glove-box, seven sorption experiments were conducted with $50 \mu \mathrm{M} \mathrm{Pb}, \mathrm{MX}-80$ clay at 5.7-9.4 pH range. For these samples, an aliquot of the clay stock dispersion was degassed by letting it equilibrate with the glove-box atmosphere for ten days. In addition, three control experiments were prepared without clay at $\mathrm{pH} 6.3$ and 9.6. They were prepared with the same procedure as described above except that the clay stock dispersion was replaced by $0.1 \mathrm{M} \mathrm{NaCl}$ solutions.

After equilibration, samples were centrifuged at $\sim 12700$ g for 15 minutes in Sigma $6 \mathrm{~K} 10$ Bioblock Scientific centrifuge. For the samples equilibrated at $67^{\circ} \mathrm{C}$ the centrifuge temperature was set at $40{ }^{\circ} \mathrm{C}$ (the maximum value), and the samples were then put back into the dry bath heater at $67^{\circ} \mathrm{C}$ for a few hours. $\mathrm{pH}$ was measured at $67^{\circ} \mathrm{C}$ after calibration of the electrode response at $67^{\circ} \mathrm{C}$. Then a $5 \mathrm{~mL}$ aliquot of supernatant was acidified with $\sim 20 \mu \mathrm{L}$ of $65 \% \mathrm{M}$ $\mathrm{HNO}_{3}$ in polystyrene tubes for $\mathrm{Pb}$ measurements. Another $5 \mathrm{~mL}$ aliquot was preserved without acidification for measurements (especially alkalinity). The volume of $\mathrm{HNO}_{3}$ solution added was taken into account for correcting the measurement of final $\mathrm{Pb}$ concentration. Additional control experiments without addition of $\mathrm{Pb}$ solution made it possible to measure the release of $\mathrm{Pb}$ into solution naturally present in the clay minerals.

In addition to the samples investigated with the above procedure, some tests were also run to study the effect of the order of reagent addition ( $\mathrm{pH}$ set before or after $\mathrm{Pb}$ addition), as well as the presence of $\mathrm{pH}$ buffers (sodium acetate/acetic acid at $\mathrm{pH}$ 3.6-4.6, MES at $\mathrm{pH} 5.5-6$, and MOPS at $\mathrm{pH}$ 6.5-7), i.e. buffers whose use has been frequently reported in adsorption experiments described in the literature (Baeyens and Bradbury 1997, Marques Fernandes et al. 2016) $)$ and filtering $(0.1 \mu \mathrm{M}$ Millex Syringe filters $)$ the supernatant before $\mathrm{Pb}$ measurement. All of these tests were carried out with Kunipia-P montmorillonite.

\subsection{Concentration and $\mathrm{pH}$ Measurements}

An InLab micro electrode (Mettler Toledo) was used to measure the final $\mathrm{pH}$ in the supernatant of centrifuged dispersions. Before use, the tubes dedicated to $\mathrm{Pb}$ measurements were washed with $5 \% \mathrm{HNO}_{3}$ acid and then rinsed repeatedly with Milli-Q water. $\mathrm{Pb}$ concentrations were measured by furnace atomic absorption spectroscopy (AAS $220 \mathrm{Z}$, Spectra AA) or by inductively coupled-plasma mass spectrometry for the lowest 
concentrations (ICP-MS-NEXION 350 X, Perkin Elmer). The comparison of AAS and ICP-

241 MS independent measurement results also made it possible to control the accuracy of the measurements. Alkalinity was measured with an automatic titrator ( 736 GP Titrino Metrohm), using the Gran method. Dissolved inorganic carbon (DIC) concentrations were calculated from alkalinity and $\mathrm{pH}$ values.

\subsection{Quantification of Adsorption}

Surface coverage $\left(C_{\text {ads }}\right.$ in mol $\left.\cdot \mathrm{kg}^{-1}\right)$ and distribution coefficient $\left(\mathrm{R}_{\mathrm{D}}\right.$ in $\left.\mathrm{L} \cdot \mathrm{kg}^{-1}\right)$ were calculated from the initial $\mathrm{Pb}$ concentration $\left(\mathrm{C}_{\text {init }}\right.$ in $\left.\mathrm{mol} \cdot \mathrm{L}^{-1}\right)$, the equilibrium $\mathrm{Pb}$ concentration in solution $\left(\mathrm{C}_{\mathrm{eq}}\right.$ in $\left.\mathrm{mol} \cdot \mathrm{L}^{-1}\right)$ and the solid/liquid ratio $\left(\mathrm{R}_{\mathrm{SL}}\right.$ in $\left.\mathrm{kg} \cdot \mathrm{L}^{-1}\right)$.

$$
\begin{gathered}
C_{a d s}=\frac{C_{i n i t}-C_{e q}}{R_{S L}} \\
R_{D}=\frac{C_{i n i t}-C_{e q}}{C_{e q} \times R_{S L}}
\end{gathered}
$$

The error bands were calculated as follows (Tournassat et al. 2013):

$$
\begin{gathered}
u C_{a d s}=\frac{\sqrt{u C_{\text {init }}^{2}+u C_{e q}^{2}}}{R_{S L}} ; \Delta C_{a d s}=k \times u C_{a d s} \\
u R_{D}=\sqrt{\left(\frac{u C_{\text {init }}}{R_{S L} \cdot C_{e q}}\right)^{2}+\left(\frac{C_{\text {init }} \cdot u C_{e q}}{R_{S L} \cdot C_{e q}{ }^{2}}\right)^{2}} ; \Delta R_{D}=k \times R_{D}
\end{gathered}
$$

Where $\Delta$ values are the considered error bands, $k$ is the coverage factor $(\mathrm{k}=2$, corresponding to a $95 \%$ confidence interval), $u C_{i n i t}$ and $u C_{e q}$ are the uncertainties associated with the total concentration and the equilibrium concentration respectively, considered at $2 \%$ of the values. Uncertainty of the $R_{S L}$ was neglected.

\subsection{Modeling}

The modeling of the data combined ion exchange on basal sites, surface complexation on edge sites and precipitation reactions. Geochemical modeling was carried out with PHREEQC v3 (Parkhurst and Appelo 2013). The ThermoChimie v9b database (Giffaut et al. 2014) was used to calculate aqueous and precipitation/dissolution reactions. The influence of the complexation reactions in solution (e.g. $\mathrm{Pb}^{2+}$ with $\mathrm{Cl}^{-}$and $\mathrm{HCO}_{3}^{-}$) was thus explicitly taken into account. The Debye-Huckel equation was used for ionic strength correction. In Thermochimie, the temperature dependence of the equilibrium constants is estimated with the Van't Hoff equation. A standard temperature of $25^{\circ} \mathrm{C}$ was considered to model the data obtained at $20^{\circ} \mathrm{C}$. The software PHREEPLOT was used to plot predominance diagrams and contour plots (Kinniburgh and Cooper 2011).

Sorption model parameters for ion exchange and surface complexation reactions were determined by a fitting procedure applied to the whole dataset, starting from the determination of selectivity coefficients for cation exchange reactions using experimental data sets at two different ionic strength and at low $\mathrm{pH}$ values. Then the surface complexation constants and the surface site densities were determined with the data measured in the $\mathrm{pH}$ range from 4 to 6.5 . 


\section{Results}

272

273

274

275

276

277

278

279

280

281

282

283

284

285

286

287

288

289

290

291

292

293

294

295

296

297

298

299

300

301

302

303

304

305

306

307

308

\subsection{Influence of Experimental Procedures on $\mathrm{Pb}$ Retention}

\subsection{1. pH Buffers and Filtration}

Adding buffers to stabilize the $\mathrm{pH}$ had a marked impact on the measured $\mathrm{R}_{\mathrm{D}}$ and surface coverage $\left(\mathrm{C}_{\mathrm{ads}}\right)$ values (Figure $\mathrm{S}-1$, Supporting information), contrasting with the results of previous studies, which showed that the presence of $\mathrm{pH}$-buffers had little or no effect on the adsorption of divalent metals on montmorillonite (Baeyens and Bradbury 1997). Because it was very difficult to fix the $\mathrm{pH}$ at a desired value without using a buffer, this experimental artefact prevented the acquisition of a $\mathrm{Pb}$ adsorption edge as a function of concentration and at constant $\mathrm{pH}$. Instead, the $\mathrm{Pb}$ adsorption edge was established at constant $\mathrm{Pb}$ concentration and as a function of $\mathrm{pH}$, with various total $\mathrm{Pb}$ concentrations from $1 \mu \mathrm{M}$ to $50 \mu \mathrm{M}$. Using filters had little impact on the $\mathrm{Pb}$ concentration measurements at equilibrium. Consequently, $\mathrm{Pb}$ concentration was measured without filtering of the supernatant in agreement with procedures frequently reported in clay adsorption studies (Baeyens and Bradbury 1995, Yang et al. 2010, Marques Fernandes et al. 2015).

\subsubsection{Order of Addition of Reagents}

The order of addition of reagents had a big impact on the measured $\mathrm{R}_{\mathrm{D}}$ values especially for $\mathrm{pH}$ values above 6, i.e. for $\mathrm{pH}$ values that necessitated the addition of $\mathrm{NaOH}$ to reach the target value: the addition of $\mathrm{Pb}$ prior to $\mathrm{pH}$ adjustment increased the measured retention of $\mathrm{Pb}$ compared to the case where $\mathrm{Pb}$ was added after $\mathrm{pH}$ adjustment. (Figure $\mathrm{S}-2$ ). Consequently, the $\mathrm{pH}$ adjustments were done before spiking the solution with $\mathrm{Pb}$ in all experiments reported in the following.

\subsection{Pb Retention Behavior under Varying Chemical Conditions}

Similar trends were observed for $\mathrm{pH}$-dependent retention isotherms with all clay minerals at different ionic strengths (Figure 1) and at different total $\mathrm{Pb}$ concentrations. At room temperature, $\mathrm{Pb}$ retention increased with decreasing ionic strength at constant $\mathrm{Pb}$ concentration and constant $\mathrm{pH}$, and it increased with increasing $\mathrm{pH}$ at constant ionic strength and total $\mathrm{Pb}$ concentration. Although similar in shape for all clay samples, $\mathrm{Pb}$ retention curves exhibited contrasted retention maxima depending on the clay samples' nature (Figure 2). Kunipia and MX-80 had very similar affinity for $\mathrm{Pb}$ and were the materials tested that had lowest $\mathrm{Pb}$ affinity. IdP had the greatest affinity, and COx clay sample exhibited retention behavior intermediate between montmorillonite and IdP, in qualitative agreement with its mineralogical composition containing illite and illite smectite mixed layers. The effect of ionic strength on retention was maximum at $\mathrm{pH}$ value below 5 for montmorillonite (MX-80 and Kunipia), and was otherwise limited. Changes in ionic strength had little effect on overall $\mathrm{Pb}$ retention for IdP and COx clay samples. A temperature increase had also no significant effect on $\mathrm{Pb}$ adsorption for all clay types in the investigated conditions $\left(\mathrm{C}_{\mathrm{tot}}=1 \mu \mathrm{M}, 0.1 \mathrm{M}\right.$ $\mathrm{NaCl}$, and $67^{\circ} \mathrm{C}$ ) (Figure 3). 

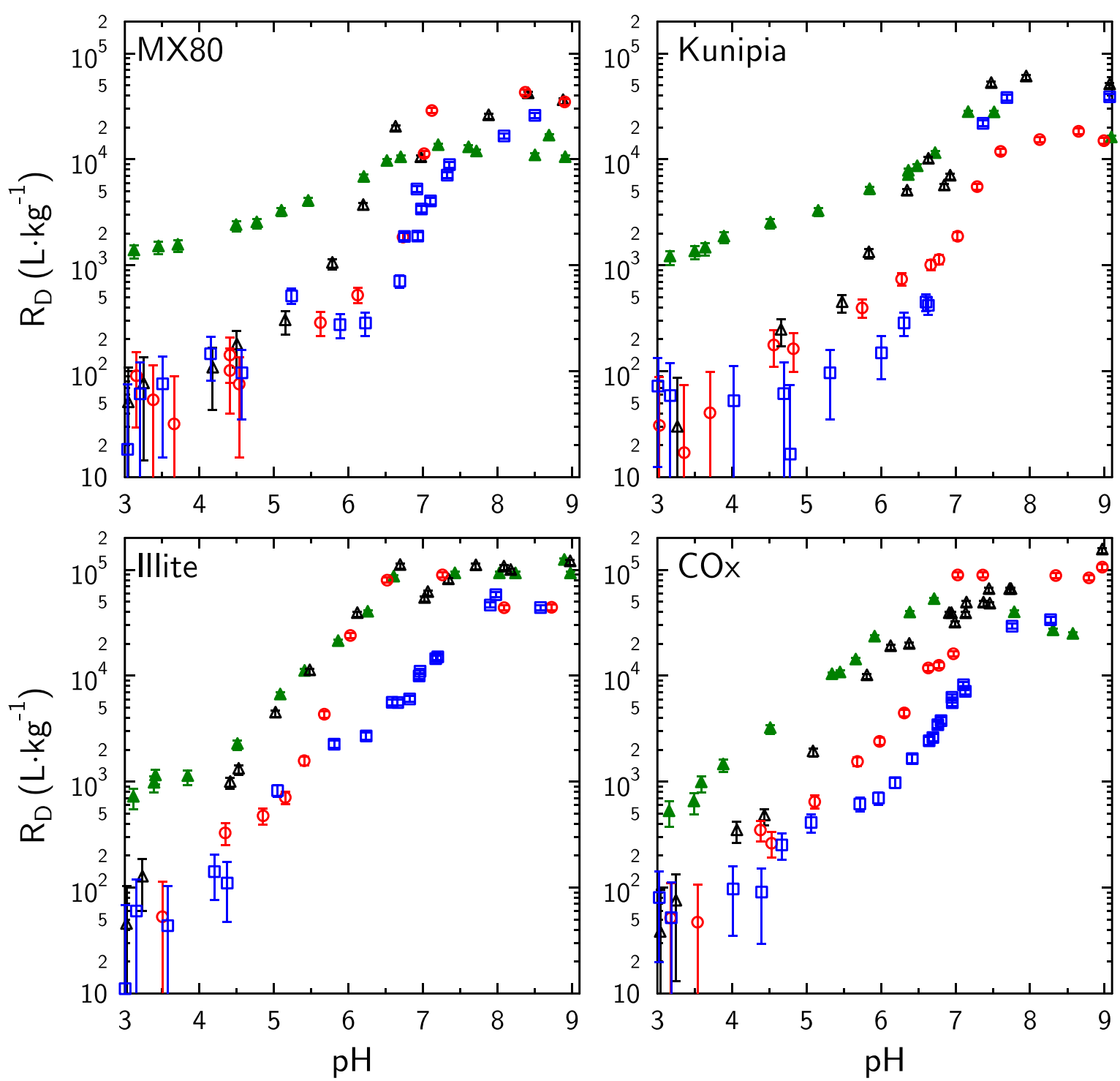

Figure 1. Comparisons of experimental datasets for $\mathrm{Pb}$ retention at room temperature on $\mathrm{MX}$ symbols; $0.1 \mathrm{M} \mathrm{NaCl}=$ open symbols), and total $\mathrm{Pb}$ initial concentrations (triangle symbols: 1 $\mu \mathrm{M}$; circle symbols: $10 \mu \mathrm{M}$; square symbols: $50 \mu \mathrm{M}$ ) (Details of the datasets are given in supporting information file). 


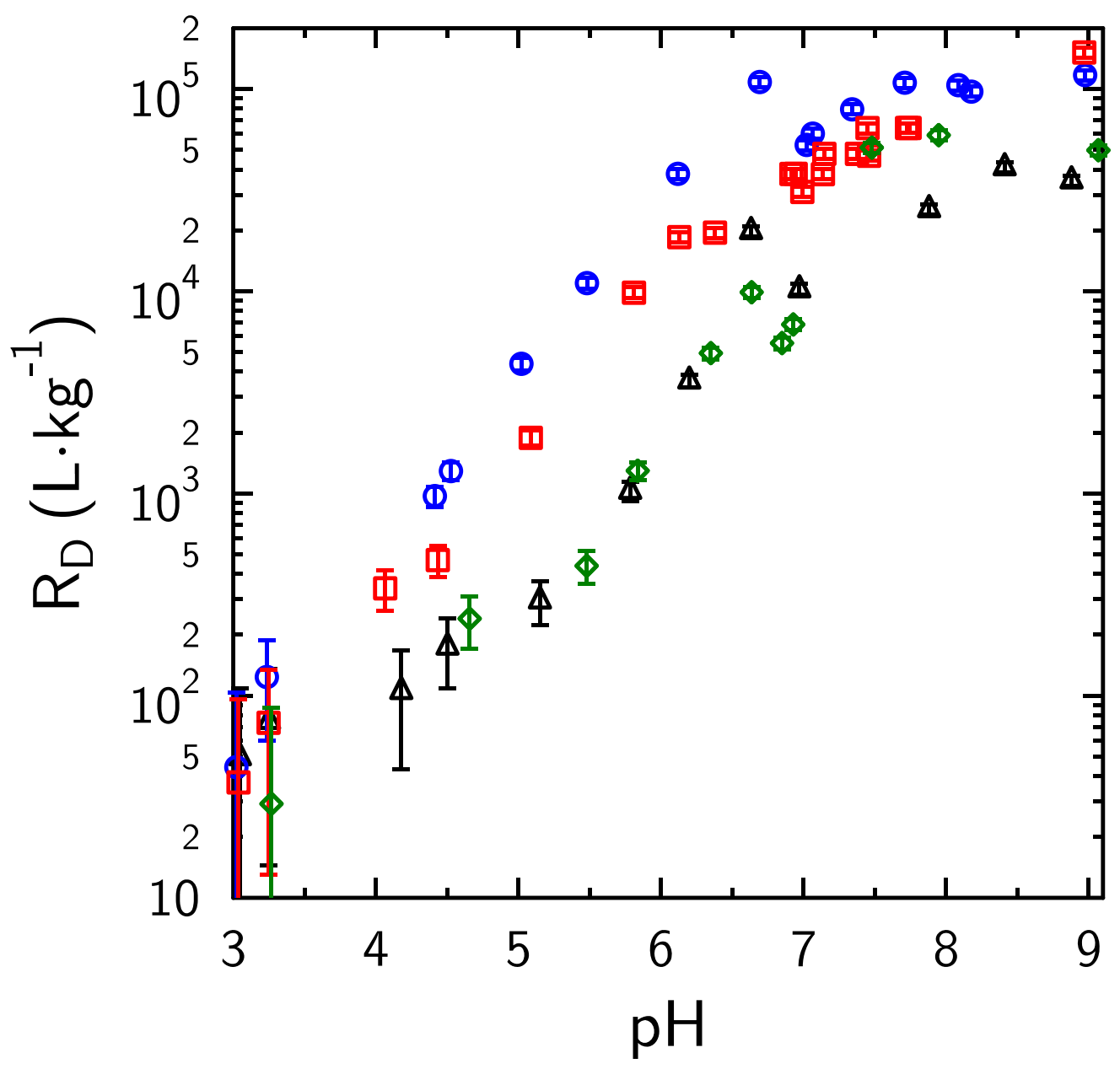

316 Figure 2. Comparison of $\mathrm{Pb}$ retention on MX-80 (triangles), Kunipia (diamonds), IdP (circles) 317 and $\mathrm{COx}$ clay (squares) at room temperature as a function of $\mathrm{pH}$, in the presence of $0.1 \mathrm{M}$ $318 \mathrm{NaCl}$ background electrolyte and a total $\mathrm{Pb}$ concentration of $1 \mu \mathrm{M}$. 

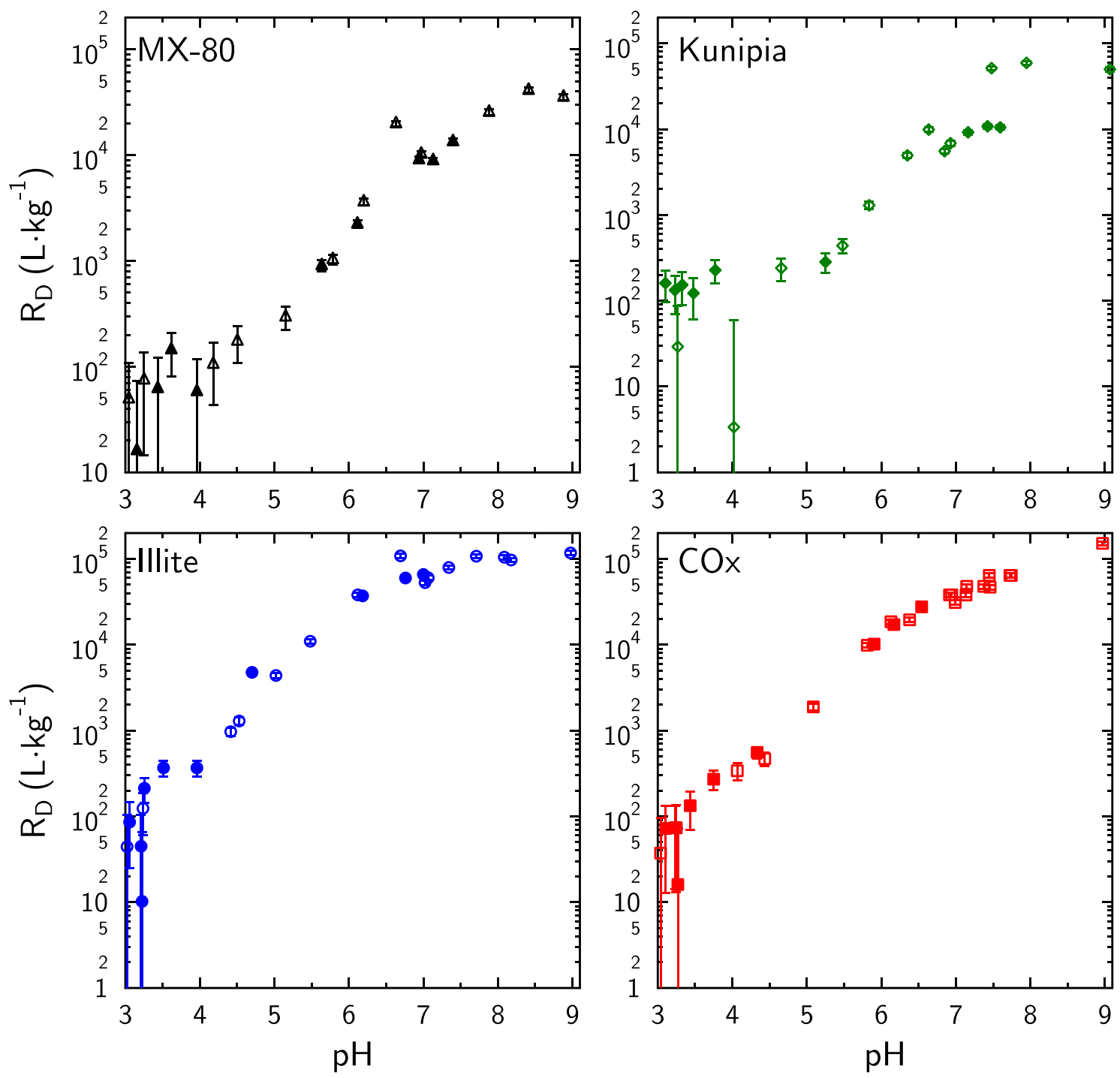

Figure 3. Pb retention on MX-80 (triangles), Kunipia (diamonds), IdP (circles) and COx clay (squares) at room temperature (open symbols) and $67^{\circ} \mathrm{C}$ (closed symbols) as a function of $\mathrm{pH}$, in the presence of $0.1 \mathrm{M} \mathrm{NaCl}$ background electrolyte and a total $\mathrm{Pb}$ concentration of $1 \mu \mathrm{M}$ (Details of the datasets are given in supporting information file).

\subsection{Alkalinity and DIC concentrations}

Samples tested at room temperature had alkalinity values within the range $0.17-0.31$ meq. $\mathrm{L}^{-1}$ in the presence or absence of clay and for $\mathrm{pH}$ ranging from $\sim 5.5$ to 9 . These alkalinity values corresponded to calculated DIC concentrations that were consistent with a near equilibrium of stock solutions and dispersion with atmospheric $\mathrm{CO}_{2}\left(\log \mathrm{pCO}_{2}=-3.5\right)$ before the adsorption experiment (Figure 4, bottom) at $\mathrm{pH}$ 7-8. For this reason, a constant DIC concentration of $0.25 \mathrm{mmol} \cdot \mathrm{L}^{-1}\left(-3.6\right.$ in $\log _{10}$ scale) was considered to be present in all samples. Despite the care to exclude $\mathrm{CO}_{2}$ from the experiment conducted in the glove-box, alkalinity/DIC concentration values were similar to values obtained in experiments conducted outside the glove-box (Figure 4, bottom). This observation echoes the results of Tournassat et al. (2018) on U(VI) adsorption experiments on montmorillonite, where the DIC concentrations measured in " $\mathrm{CO}_{2}$-free" experiment ranged from $8.210^{-3}$ to $6.210^{-2} \mathrm{mmol} \cdot \mathrm{L}^{-1}$ in the $\mathrm{pH}$ range 3.9-9.9. 


\section{Modelling and Discussion}

\subsection{Adsorption versus (Co-)Precipitation}

339 It is well known that divalent heavy metals such as $\mathrm{Pb}$ can precipitate at near natural or

340 alkaline conditions depending on their concentration in the aqueous solution and on the water 341 composition (Marani et al. 1995, Echeverría et al. 2005, Sipos et al. 2008, Tournassat et al. 342 2013). Thermodynamic calculations evinced that for a total $\mathrm{Pb}$ concentration of $50 \mu \mathrm{M}, \mathrm{Pb}$ 343 precipitation was expected to occur at $\mathrm{pH} \sim 6.7$ in the presence of atmospheric $\mathrm{CO}_{2}$ partial 344 pressure $\left(\operatorname{logpCO}_{2}=-3.5\right)$ (Figure 4, top). Therefore $\mathrm{Pb}$ precipitation could have occurred in 345 the form of cerussite $\left(\mathrm{PbCO}_{3}\right)$, hydrocerussite $\left(\mathrm{Pb}_{3}\left(\mathrm{CO}_{3}\right)_{2}(\mathrm{OH})_{2}\right)$ or laurionite $(\mathrm{PbClOH})$ 346 above $\mathrm{pH} 6.7$ for the highest investigated total $\mathrm{Pb}$ concentration $(50 \mu \mathrm{M})$. Based on 347 experiments with direct precipitation in solution, Marani et al. (1995) showed that cerussite 348 and hydrocerussite can indeed form easily in conditions similar to the experimental conditions 349 in this work. $\mathrm{Pb}$ (co-)precipitation may explain the discrepancy observed between 350 experiments with $\mathrm{Pb}$ addition made before or after $\mathrm{pH}$ adjustment (Figure S-2): increasing the $351 \mathrm{pH}$ after $\mathrm{Pb}$ addition could have been responsible for (surface) precipitation when the 352 concentrated $\mathrm{NaOH}$ solution entered into contact with the clay- $\mathrm{Pb}$ dispersion. Such (surface) 353 precipitation and/or surface polymerization in the presence of clay minerals was evidenced in 354 previous studies using EXAFS (Strawn and Sparks 1999) and by direct SEM observations 355 (Echeverría et al. 2005), but with total $\mathrm{Pb}$ concentrations higher than those used in this study. 356 In practice, data interpretation with an adsorption model needs to be restricted to the $\mathrm{pH}$ 357 domain where precipitation does not occur (Tournassat et al. 2013). Consequently, the 358 complexation of free $\mathrm{Pb}^{2+}$ by bicarbonate and carbonate in solution as well as the possible 359 precipitation of $\mathrm{Pb}$ carbonate minerals must be taken into account for the quantitative 360 interpretation of the results with SCM. 

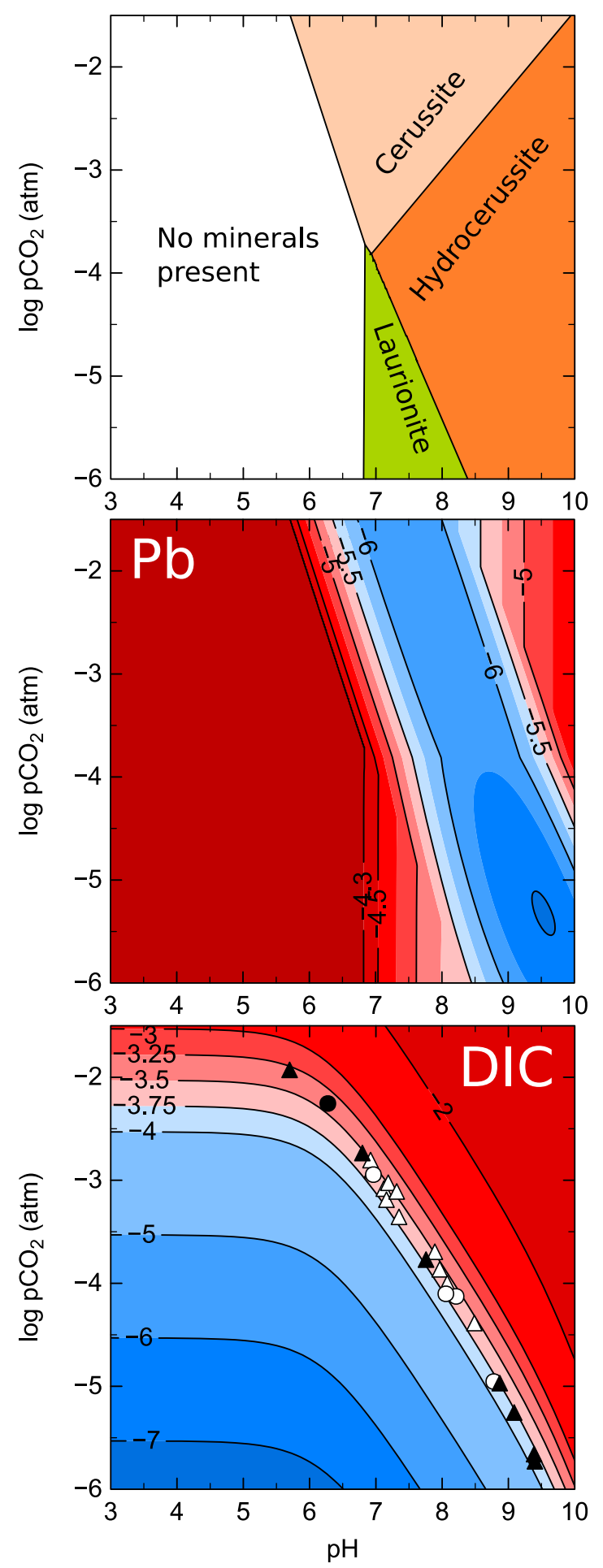

362 Figure 4. Top figure: $\mathrm{Pb}$ solid phase predominance as a function of $\mathrm{pH}$ and $\mathrm{pCO}_{2}$ in the absence of adsorption processes. Minerals allowed to precipitate: cerussite $\left(\mathrm{PbCO}_{3}\right)$, hydrocerussite $\left(\mathrm{Pb}_{3}\left(\mathrm{CO}_{3}\right)_{2}(\mathrm{OH})_{2}\right)$, cotunnite $\left(\mathrm{PbCl}_{2}\right)$, laurionite $(\mathrm{PbClOH})$, paralaurionite $(\mathrm{PbClOH})$ and $\mathrm{Pb}(\mathrm{OH})_{2}(\mathrm{~s})$ : Total $\mathrm{Pb}$ concentration: $50 \mu \mathrm{M}\left(\log [\mathrm{Pb}]_{\text {tot }}=-4.3\right)$. Middle figure: Contour plot of calculated $\mathrm{Pb}$ concentration in solution ( $\log _{10}$ scale) as a function of $\mathrm{pH}$ and $\mathrm{pCO}_{2}$. The color change between two contour lines indicates a change of $0.25 \log _{10}$ scale units. Bottom figure: Contour plot of calculated DIC concentration as a function of $\mathrm{pH}$ and $\mathrm{pCO}_{2}\left(\log _{10}\right.$ scale). Symbols correspond to experimental measurements in the presence (triangles) or absence (circles) of clay and with sample preparation in contact with atmosphere 
(white symbols) or in the glove-box (black symbols). The background electrolyte concentration is $0.1 \mathrm{M} \mathrm{NaCl}$ for all figures. The data, obtained with correct reagent addition order, and in conditions where $\mathrm{Pb}$ precipitation was not expected from a thermodynamic point of view, were in qualitative agreement with the adsorption mechanisms of divalent metals on clay mineral surfaces that have been identified for many years, using a combination of wet chemistry experiments with diffractometric and spectrometric characterization (Tournassat et al. 2013, Borisover and Davis 2015). According to these mechanisms, cation exchange on basal and interlayer surfaces was responsible for $\mathrm{Pb}$ adsorption at low $\mathrm{pH}$ (below 3 to 5 depending on the clay material) where nearly constant $R_{D}$ values were measured. As expected, changes in ionic strength impacted $R_{D}$ values more for montmorillonite than for illite (Figure 2) because the cation exchange capacity of montmorillonite is higher than that of illite. $\mathrm{R}_{\mathrm{D}}$ values with $\mathrm{COx}$ clay, which has intermediate cation exchange capacity between montmorillonite and illite, accordingly exhibited intermediate behavior. Surface complexation on the edge surfaces was responsible for $\mathrm{Pb}$ adsorption at higher $\mathrm{pH}$, and a strong influence of $\mathrm{pH}$ on $\mathrm{R}_{\mathrm{D}}$ values was recorded for all four types of samples. Note also that little effect of ionic strength was recorded.

\subsection{Modeling $\mathrm{Pb}$ adsorption on clay mineral surfaces}

\subsubsection{Choice of model}

SCMs quantify adsorption processes based on a set of protonation/deprotonation and adsorption reactions, which links the surface charge to the surface potential and the specific surface area where the reactions taken place. SCMs were initially developed to model the reactivity of oxide surfaces and gave rise to numerous variants, of which the most extensively used are the Constant Capacitance Model - CCM - (Goldberg 2013), Diffuse-Double Layer model - DDL - (Dzombak and Morel 1990), the Triple Layer Model - TLM - (Davis and Kent 1990), and the Charge Distribution model - CD(-MUSIC) - (Hiemstra and Van Riemsdijk 1996). Numerous SCM using these classical approaches have been published in the literature to describe adsorption on clay mineral surfaces (Zachara and Smith 1994, Turner et al. 1998, Barbier et al. 2000, Ikhsan et al. 2005, Gu and Evans 2007, Gu et al. 2010, Akafia et al. 2011) These models, however, have not taken into account the unique characteristics of electrostatic surface potentials that occur at clay edge sites, where the electrostatic surface potential of basal plane cation exchange sites influences the surface potential of neighboring edge sites, i.e. the 'spillover' effect (Secor and Radke 1985, Chang and Sposito 1996). Indeed, the spillover effect invalidates the use of classical SCMs such as DDL, CCM and TLM to quantify the effect of clay edge surface charge potential on adsorption (Bourg et al. 2007, Tournassat et al. 2013, 2016). The inadequacy of the classical DLM model to reproduce divalent metal adsorption on montmorillonite surface in a wide range of $\mathrm{pH}$ and ionic strength conditions has been put forward repeatedly for more than twenty years (Baeyens and Bradbury 1997, Akafia et al. 2011). Only recently, a SCM that included the spillover effect in the evaluation of the surface potential was successfully applied to quantify U(VI) adsorption on montmorillonite in a wide range of $\mathrm{pH}$, ionic strength and DIC concentration conditions (Tournassat et al. 2018). In this study, quantifying $\mathrm{Pb}$ adsorption were investigated on montmorillonite samples, but also on illite samples and on a natural assemblage of illite, 
illite/smectite mixed layer mineral (IS) and smectite. A second objective was the prediction of adsorption properties of natural Callovian-Oxfordian claystone in the presence of in situ conditions $\left(\mathrm{pH} \sim 7.2\right.$ and $\mathrm{pCO}_{2} \sim 10^{-2}$ bar at $25^{\circ} \mathrm{C}$ ). Unfortunately, the above mentioned 'spillover' model has been developed only for montmorillonite, not for illite. Alternatively, instead of a comprehensive model that includes as many physically grounded mechanisms as possible, simpler, yet successful, models can be developed. A good example of this kind of model is the 2SPNE SC/CE Model (2 site protolysis non-electrostatic surface complexation and cation exchange model) developed by Bradbury and Baeyens (1997). The authors noted that their data were better fitted if the electrostatic term was canceled. In this model, surface complexation of divalent metals on the clay mineral edge surfaces was ascribed to two types of sites: high-energy (strong) sites that are present in low amounts (typically $\sim 2 \mathrm{mmol} \cdot \mathrm{kg}^{-1}$ ) and have high affinity for the adsorbate, and low energy (weak) sites that, conversely, are present in large amounts (typically $\sim 50 \mathrm{mmol} \cdot \mathrm{kg}^{-1}$ ) and have low affinity for the adsorbate. Because this type of model aims for efficiency and simplicity and because it does not include physical features that play a significant role in the adsorption mechanism, it must fulfil the parsimony rule, i.e. that the least number of parameters must be considered to fit the data (Tournassat et al. 2013). In this modeling effort, this approach was applied together with a non-electrostatic model in order to fit the adsorption data on IdP and MX-80 samples, and then it was used to predict the adsorption on Kunipia and COx clay. The component additivity (CA) approach was used to model the adsorption on the COx clay with the assumption that the reactivity of edge site of illite/smectite mixed layers was similar to this combination of montmorillonite and illite layer edges (Davis et al. 2004, Chen et al. 2014a, 2014b).

\subsubsection{Modeling the data at room temperature}

A very simple model with only one cation exchange site and one edge surface complexation site (Table 2) was sufficient to fit all the data at room temperature (Figure 5 and Figure 6). The cation exchange selectivity coefficients for $\mathrm{Pb}$ on $\mathrm{MX}-80$ and $\mathrm{IdP}(\log \mathrm{K}=0.6$ and 0.7 respectively) had values similar to values reported for other divalent metals (e.g. $\mathrm{Ni}, \mathrm{Cu}, \mathrm{Co}$, Zn, Fe) (Fletcher and Sposito 1989, Bradbury and Baeyens 2005a, Charlet and Tournassat 2005, Tournassat et al. 2009). The surface complexation site density values ( 0.01 and 0.035 $\mathrm{mol} \cdot \mathrm{kg}^{-1}$ for MX-80 and IdP respectively) were in the range of low energy site densities described in the literature for montmorillonite and illite, indicating that high energy sites may not be present on these samples or may be present at very low site density (Baeyens and Bradbury 1997, Bradbury and Baeyens 2005b). The presence of an additional high energy adsorption site in this model did not improve markedly the overall fitting of the data, so it was decided not to include it. The protonation of the surface was not needed in this model to fit the data (Tournassat et al. 2013). In the presence of high total $\mathrm{Pb}$ concentration and near neutral to alkaline $\mathrm{pH}$ values, (hydro)cerussite precipitation was in quantitative agreement with the observed sharp $\mathrm{R}_{\mathrm{D}}$ increase. Retention data on Kunipia were adequately predicted with the same model as for MX-80. Retention data on COx clay were well predicted with a model mixing $50 \%$ of illite and $50 \%$ of montmorillonite. These proportions correspond roughly to the proportion of, respectively, illite and illite smectite mixed layers minerals in the clay fraction of the COx clay (Gaucher et al. 2004, Chen et al. 2014a) and indicate that the 
reactivity of illite smectite mixed layers minerals can be modeled with edge surface 457 adsorption properties similar to those of montmorillonite.

458 Table 2. Parameters used in the non-electrostatic SCM at $25^{\circ} \mathrm{C}$ (values in parenthesis are for $\left.45967^{\circ} \mathrm{C}\right)$.

Montmorillonite Illite

\begin{tabular}{|c|c|c|}
\hline \multicolumn{3}{|l|}{ Cation exchange } \\
\hline $\mathrm{CEC}\left(\mathrm{X}^{-}\right.$site density) in $\mathrm{mol} \cdot \mathrm{kg}^{-1}$ & $0.78^{(1)}$ & $0.2^{(2)}$ \\
\hline Reactions & $\log \mathrm{K}$ & \\
\hline $2 \mathrm{XNa}+\mathrm{Pb}^{2+}=\mathrm{X}_{2} \mathrm{~Pb}+2 \mathrm{Na}^{+}$ & $0.6(0.9)$ & $0.7(0.9)$ \\
\hline $2 \mathrm{XNa}+\mathrm{Mg}^{2+}=\mathrm{X}_{2} \mathrm{Mg}+2 \mathrm{Na}^{+}$ & 0.6 & 0.7 \\
\hline $2 \mathrm{XNa}+\mathrm{Ca}^{2+}=\mathrm{X}_{2} \mathrm{Ca}+2 \mathrm{Na}^{+}$ & 0.5 & 0.5 \\
\hline \multicolumn{3}{|l|}{ Edge surface complexation } \\
\hline Site density $(>\mathrm{S})$ in $\mathrm{mol} \cdot \mathrm{kg}^{-1}$ & 0.01 & 0.035 \\
\hline Reactions & $\log \mathrm{K}$ & \\
\hline$>\mathrm{SOH}=>\mathrm{SO}^{-}+\mathrm{H}^{+}$ & -8.1 & -6.6 \\
\hline$>\mathrm{SOH}+\mathrm{Pb}^{2+}=>\mathrm{SOPb}^{+}+\mathrm{H}^{+}$ & $0(0.2)$ & $0.6(0.9)$ \\
\hline$>\mathrm{SOH}+\mathrm{Pb}^{2+}+\mathrm{H}_{2} \mathrm{O}=>\mathrm{SOPb}(\mathrm{OH})+2 \mathrm{H}^{+}$ & Not necessary & $-7.2(-6.7)$ \\
\hline
\end{tabular}

$461 \quad{ }^{(2)}$ (Bradbury and Baeyens 2000) 

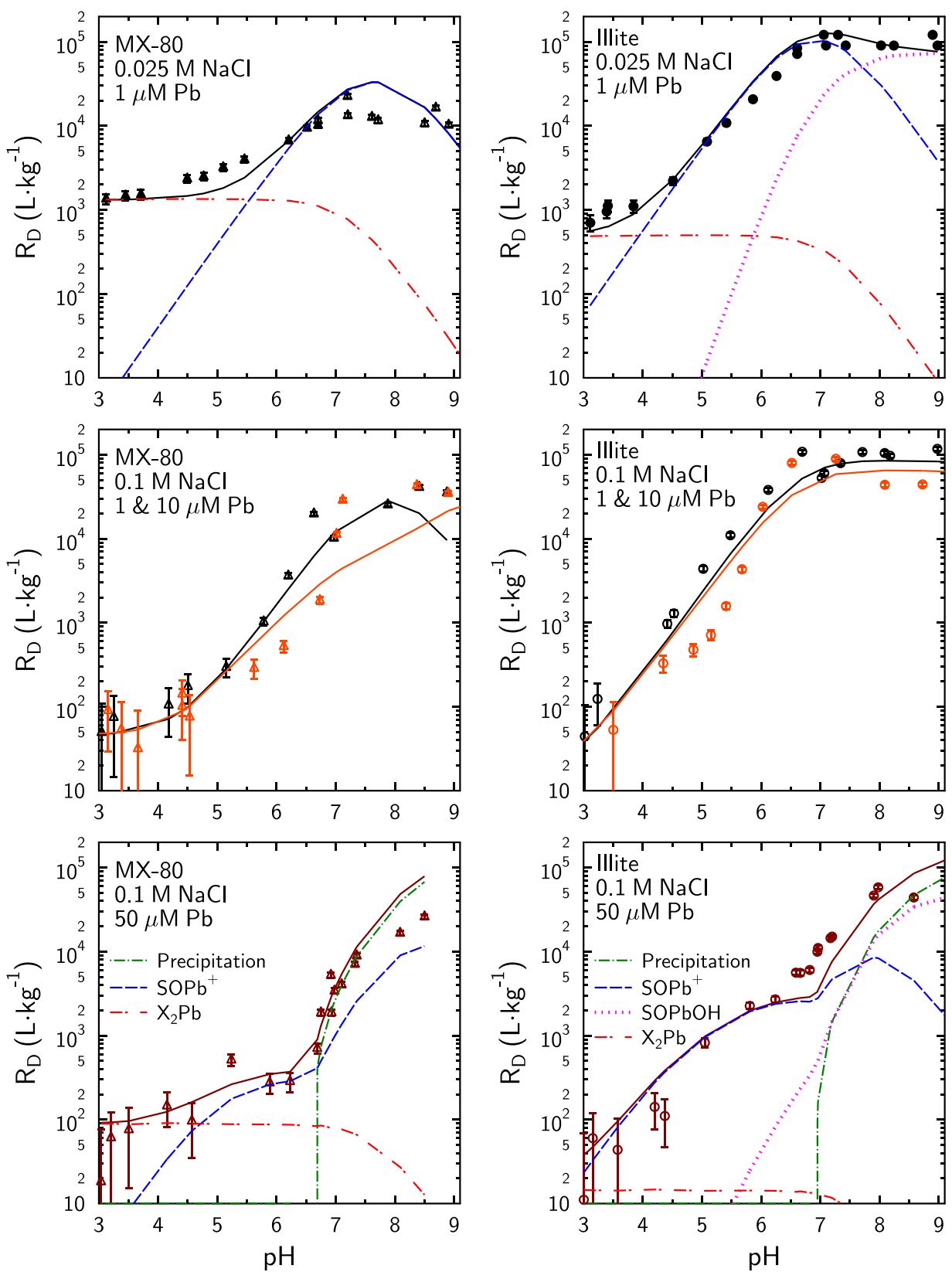

Figure 5. Modeling of $\mathrm{Pb}$ adsorption and precipitation at room temperature according to the parameters given in Table 2 for MX-80 (left) and illite (right). 

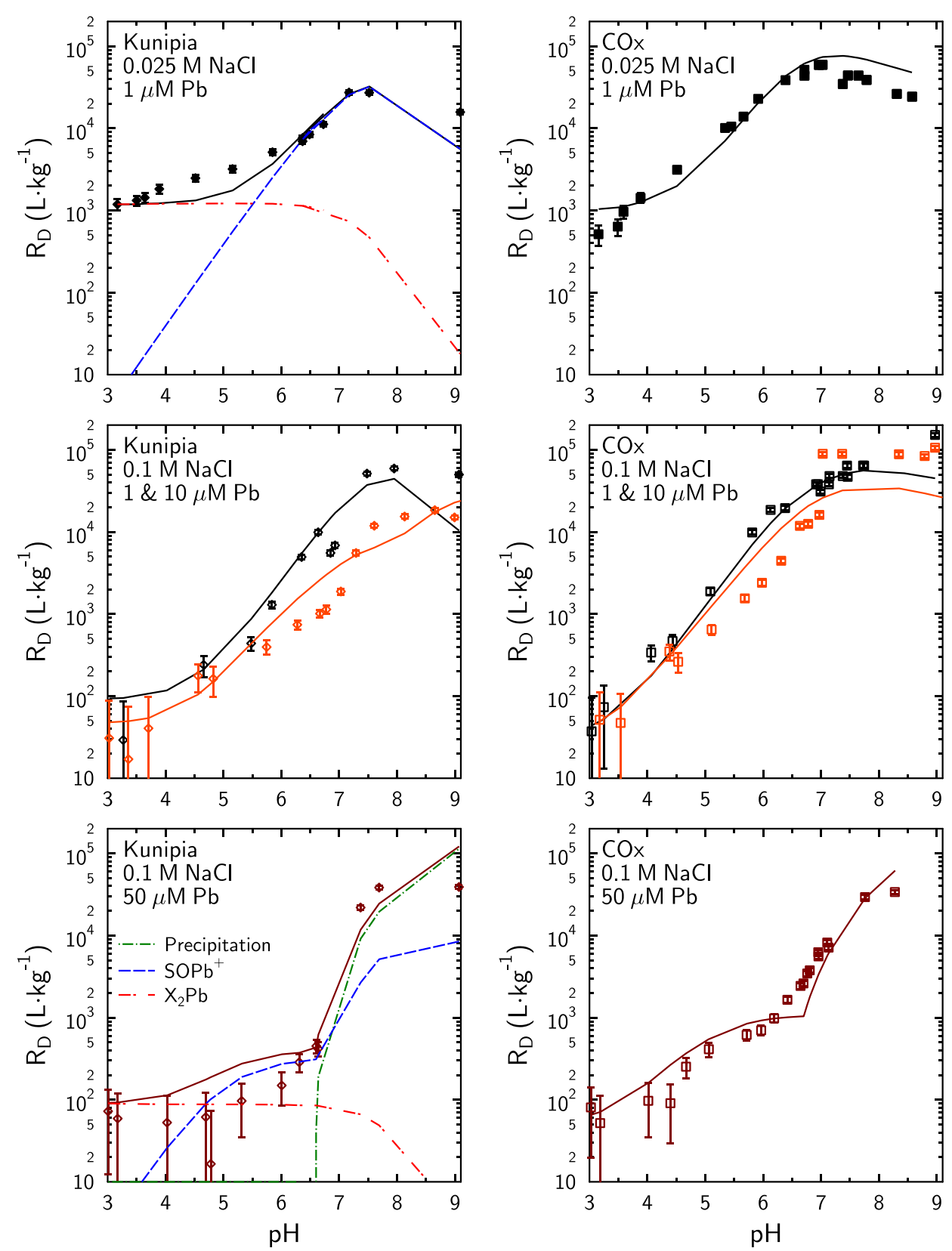

Figure 6. Model prediction for Pb adsorption / precipitation on Kunipia-P (left) and COx clay (right) at room temperature. Model parameters for Kunipia-P are the same as for $\mathrm{MX}-80 . \mathrm{Pb}$ adsorption on COx clay was modeled with an illite surface contribution of $50 \%$ and a smectite surface (montmorillonite) contribution of $50 \%$.

\subsubsection{Modeling the data at $67^{\circ} \mathrm{C}$}

A temperature increase at fixed $\mathrm{pH}$ and total $\mathrm{Pb}$ concentration values is responsible for a change in the $\left(\mathrm{Pb}^{2+}\right) /\left(\mathrm{H}^{+}\right)$activity ratio, which reflects the changes in $\mathrm{Pb}$ speciation in solution and the change of water dissociation constant as a function of temperature. This change should impact the equilibrium of the reaction $>\mathrm{SOH}+\mathrm{Pb}^{2+}=>\mathrm{SOPb}^{+}+\mathrm{H}^{+} .\left(\mathrm{Pb}^{2+}\right) /\left(\mathrm{H}^{+}\right)$ changes can be tracked by looking at the value of $\left(\mathrm{Pb}^{2+}\right) /\left(\mathrm{H}^{+}\right)$at $67^{\circ} \mathrm{C}$ normalized to its value at $25^{\circ} \mathrm{C}$ at fixed $\mathrm{pH}$ and total $\mathrm{Pb}$ concentration (Figure S-3). Up to $\mathrm{pH}$ 6, the value of 
$477 \frac{\left(\mathrm{Pb}^{2+}\right) /\left(\mathrm{H}^{+}\right)_{67^{\circ} \mathrm{C}}}{\left(\mathrm{Pb}^{2+}\right) /\left(\mathrm{H}^{+}\right)_{25^{\circ} \mathrm{C}}}$ is nearly constant and close to 0.85 . For $\mathrm{pH}$ values above 6 , the value of $478 \frac{\left(\mathrm{Pb}^{2+}\right) /\left(\mathrm{H}^{+}\right)_{67^{\circ} \mathrm{C}}}{\left(\mathrm{Pb}^{2+}\right) /\left(\mathrm{H}^{+}\right)_{25^{\circ} \mathrm{C}}}$ decreases mostly because the abundance of $\mathrm{Pb}^{2+}$ compared to other $\mathrm{Pb}$ species 479 in solution decreases with increasing $\mathrm{pH}$ faster at $67^{\circ} \mathrm{C}$ than at $25^{\circ} \mathrm{C}$. A temperature increase 480 from room temperature to $67^{\circ} \mathrm{C}$ had no significant effect on $\mathrm{Pb}$ adsorption on all four clay 481 samples up to $\mathrm{pH} 7$ (Figure 3). Therefore, a slight $\log \mathrm{K}$ change was applied in this surface 482 complexation model to compensate for the change in $\left(\mathrm{Pb}^{2+}\right) /\left(\mathrm{H}^{+}\right)$activity ratio in solution 483 from room temperature to $67^{\circ} \mathrm{C}$ (Table 2, Figure 7). The $\log \mathrm{K}$ of surface complexation 484 reactions increased slightly with a temperature increase in agreement with previous 485 observations made on $\mathrm{Ni}$ adsorption (Tertre et al. 2005). It could be tempting to conclude that 486 a temperature increase is favorable to $\mathrm{Pb}$ adsorption on clay minerals. However, in a claystone 487 such as the Callovo-Oxfordian clay the $\mathrm{pH}$ value is expected to decrease from $\sim 7.2$ at 20 $48825^{\circ} \mathrm{C}$ to $\sim 6$ at $80^{\circ} \mathrm{C}$ and the DIC concentration is expected to increase from $\sim 3 \mathrm{mM}$ at 20 $48925^{\circ} \mathrm{C}$ to $\sim 15 \mathrm{mM}$ at $80^{\circ} \mathrm{C}$ (Beaucaire et al. 2012, Gailhanou et al. 2017). Overall, these 490 changes should be detrimental to $\mathrm{Pb}$ adsorption on clay mineral surfaces. Based on these 491 results, it can be estimated that $\mathrm{Pb}$ adsorption $\mathrm{R}_{\mathrm{D}}$ value should drop by approximately one 492 order of magnitude if $\mathrm{Pb}$ is present at trace concentrations. 

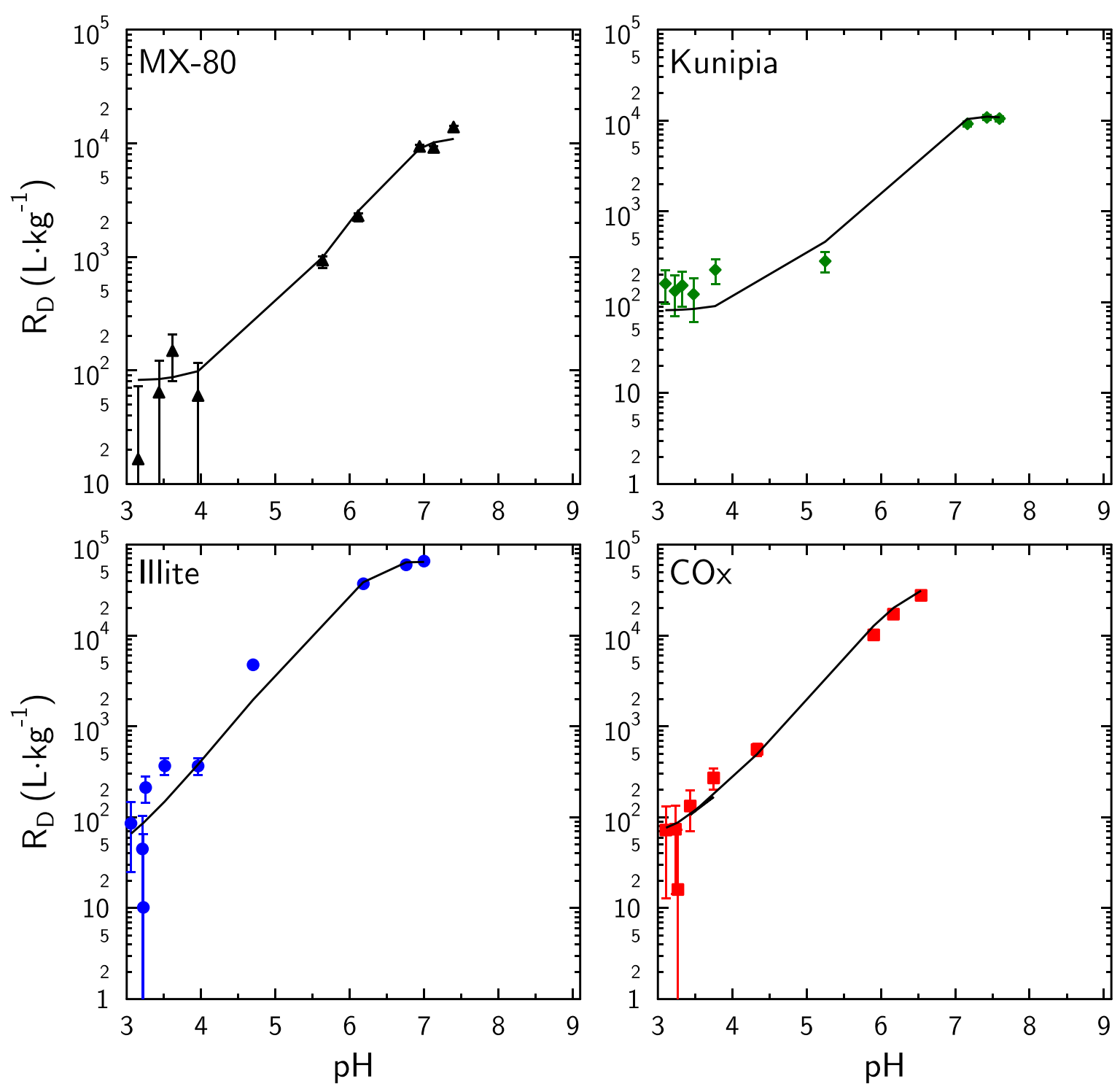

Figure 7. Model predicting $\mathrm{Pb}$ adsorption on the four clay samples at $67^{\circ} \mathrm{C}$. Parameters are 495 given in Table 2. Total $\mathrm{Pb}$ concentration: $1 \mu \mathrm{M}$. Solid/liquid ratio: $1 \mathrm{~g} \cdot \mathrm{L}^{-1}$. Background 496 electrolyte: $\mathrm{NaCl} 0.1 \mathrm{M}$.

\section{4.3. Comparison with literature data}

498 The predictions of the model were tested with $\mathrm{Pb}$ adsorption literature data obtained with 499 different montmorillonite, bentonite and illite samples in a range of experimental conditions 500 (Table 3).

501 Table 3: Experimental conditions of $\mathrm{Pb}$ absorption experiments described in the literature

\begin{tabular}{ccccccc}
\hline Clay Type & $\begin{array}{c}\text { Clay material } \\
\text { preparation } \\
\text { procedure }\end{array}$ & $\mathrm{pH}$ & $\begin{array}{c}\text { Background } \\
\text { electrolyte } \\
(\mathrm{M})\end{array}$ & $\begin{array}{c}{[\mathrm{Pb}]_{\mathrm{tot}}} \\
(\mu \mathrm{M})\end{array}$ & $\begin{array}{c}\mathrm{R}_{\mathrm{SL}} \\
\left(\mathrm{g} . \mathrm{L}^{-1}\right)\end{array}$ & Reference \\
\hline SWy-2 Mont. & None & $3-11$ & $\begin{array}{c}0.001-0.1 \\
\mathrm{NaNO}_{3}\end{array}$ & $0.1-50$ & 0.5 & (Akafia et al. 2011) \\
Fithian illite & $\begin{array}{c}<2 \mu \mathrm{m} \\
\mathrm{NaNO}_{3} \text { treated }\end{array}$ & $3-8$ & $\begin{array}{c}0.001-0.1 \\
\mathrm{NaNO}_{3}\end{array}$ & 50 & 2.97 & $\begin{array}{c}\text { (Gu and Evans } \\
\text { 2007) }\end{array}$ \\
\hline
\end{tabular}




\begin{tabular}{ccccccc}
\hline MX-80 Mont & None & $1-12$ & $0.01 \mathrm{NaNO}_{3}$ & 48.3 & $0.2 ; 0.4$ & (Xu et al. 2008) \\
$\begin{array}{c}\text { Wyoming } \\
\text { Mont. }\end{array}$ & $\begin{array}{c}<\mu \mathrm{m} \\
\mathrm{NaNO}_{3} \text { treated } \\
\text { Chinese }\end{array}$ & $3-9$ & 0.0010 .1 & 48.8 & 1.5 & (Gu et al. 2010) \\
$\begin{array}{c}<\mu \mathrm{NaNO} \\
\text { bentonite }\end{array}$ & $\begin{array}{c}1.0 \mathrm{M} \mathrm{NaCl} \\
\text { treated }\end{array}$ & & $\begin{array}{c}0.001-0.1 \\
\mathrm{NaClO} 4\end{array}$ & 72.5 & 0.5 & (Yang et al. 2010) \\
& & & & & \\
\hline
\end{tabular}

502

503

504

505

506

507

508

509

510

511

512

513

514

515

516

517

518

519

520

521

522

523

524

525

526

527

528

529

530

531

532

533

534

535

536

537

538

539

540

541

542

The data from Akafia et al. (2011), which were obtained with Swy-2 montmorillonite, were adequately predicted with this very simple model (Figure 8). As for the modeling of the data obtained in this study, the presence of a constant DIC concentration of $0.25 \mathrm{mM}$ in all $\mathrm{pH}$ range (due to atmospheric $\mathrm{CO}_{2}$ contamination) and the possible precipitation of hydrocerussite were also considered. Akafia et al.'s data at the highest total Pb concentration $(50 \mu \mathrm{M})$ and $\mathrm{pH}$ value above 6.5 were in quantitative agreement with a precipitation process (Figure 8). Their data at low $\mathrm{pH}$ and low ionic strength $(0.001 \mathrm{M} \mathrm{NaNO}$ background electrolyte) were reproduced, considering the presence of a low $\mathrm{Mg}^{2+}$ concentration competing with $\mathrm{Pb}^{2+}$ for cation exchange sites. The $\mathrm{Mg}^{2+}$ concentration was fixed at $0.1 \mathrm{mM}$ in agreement with data reported in the literature in similar experimental conditions (Baeyens and Bradbury 1995, Gu et al. 2010, Marty et al. 2011), and the same cation exchange selectivity coefficient was attributed to $\mathrm{Mg}^{2+}$ and to $\mathrm{Pb}^{2+}$ (Fletcher and Sposito 1989, Tournassat et al. 2009). The presence of $\mathrm{Mg}^{2+}$ in solution (and on the exchanger at low background electrolyte concentration) was due to the partial dissolution of the clay layers (Marty et al. 2011). The competitive presence of $\mathrm{Mg}^{2+}$ for cation exchange sites cannot be avoided, and it cannot be neglected in the modeling for data at low ionic strength (typically below 0.01 ) and low $\mathrm{pH}$. Finally, the data in the $\mathrm{pH}$ range 4 to 7 were very well fitted if the surface complexation site density was increased from 0.01 to $0.02 \mathrm{~mol} \cdot \mathrm{kg}^{-1}$ (Figure 8 ). Surface complexation site density is related to the edge specific surface area of montmorillonite layers and not to the $\mathrm{N}_{2^{-}}$ BET surface area that lumps together external basal surface area and edge surface area (Metz et al. 2005, Tournassat et al. 2015). According to Atomic Force Microscopy, Derivative Isotherm measurements and potentiometric titration data, MX-80, Kunipia-P and Swy-2 montmorillonite have edge specific surface area values of $\sim 7-12 \mathrm{~m}^{2} \cdot \mathrm{g}^{-1}, \sim 5 \mathrm{~m}^{2} \cdot \mathrm{g}^{-1}$ and $\sim 14-$ $25 \mathrm{~m}^{2} \cdot \mathrm{g}^{-1}$ respectively (Duc et al. 2005, Yokoyama et al. 2005, Le Forestier et al. 2010, Tournassat et al. 2015, 2016). This difference in surface area values is commensurable with the modeled difference in site density between MX-80/Kunipia-P and Swy-2 samples. Consequently, the agreement between the model predictions and the published data from Akafia et al. (2011) indicated that three different reference montmorillonite samples - MX80, Kunipia-P, and Swy-2 - had similar $\mathrm{Pb}$ adsorption properties, MX-80 and Kunipia-P having a smaller site density than Swy-2 because of their smaller edge specific surface area.

With the same modeling approach, the $\mathrm{Pb}$ adsorption data that were measured by $\mathrm{Gu}$ and Evans (2007) with Fithian illite were predicted correctly up to $\mathrm{pH} 6.5$ in the presence of 0.001-0.1 $\mathrm{M} \mathrm{NaNO}_{3}$ and of a $50 \mu \mathrm{M} \mathrm{Pb}$ total concentration. Above this $\mathrm{pH}$ value, the model overestimated the measured adsorption values, but this discrepancy may fall in the range of data uncertainty: first, it was difficult to estimate the uncertainty in the measurement itself, and second, data digitization may have introduced some bias especially for data at retention values close to $100 \%$, for which the discrepancy is the largest. A better data fit was obtained if the site density was reduced from 0.035 to $0.025 \mathrm{mmol} \cdot \mathrm{kg}^{-1}$ (Figure 9). Because this difference in site density is small, it can be concluded that Fithian illite and IdP had similar $\mathrm{Pb}$ adsorption properties. 
543 Some other literature data were not compatible with this model prediction. Xu et al. (2008) 544 studied $\mathrm{Pb}$ adsorption on non-purified MX-80 bentonite, i.e. a material similar to the materials 545 used in this study, except that it contained additional mineral impurities such as quartz, 546 cristobalite, feldspar and calcite, which were partly removed during the sample preparation 547 procedure in this study. $\mathrm{Xu}$ et al. (2008) used a high $\mathrm{Pb}$ to clay ratio (total $\mathrm{Pb}$ concentration 548 was $48.3 \mu \mathrm{M}$ and solid/liquid ratio was 0.2 or $\left.0.4 \mathrm{~g} \cdot \mathrm{L}^{-1}\right)$. In the experiment with $50 \mu \mathrm{M}$ total $549 \mathrm{~Pb}$ concentration and a clay concentration of $1 \mathrm{~g} \cdot \mathrm{L}^{-1}$ and $\mathrm{I}=0.01 \mathrm{M} \mathrm{NaNO}$, a site $(>\mathrm{S})$ 550 saturation effect was observed at $\mathrm{pH}<6.5$ that made it possible to refine a site density value 551 at $\sim 0.01 \mathrm{~mol} \cdot \mathrm{kg}^{-1}$ (Figure 5). At $\mathrm{pH}$ values greater than $6.5, \mathrm{~Pb}$ precipitation occurred in these 552 experimental conditions. In the experiments of $\mathrm{Xu}$ et al. (2008), such site saturation did not occur (Figure 10). If their data were modeled with a surface complexation model, the site density should have been as high as $0.15 \mathrm{~mol} \cdot \mathrm{kg}^{-1}$. Because the edge specific surface area of MX-80 is $\sim 8 \mathrm{~m}^{2} \cdot \mathrm{g}^{-1}$, this site density would correspond to a surface occupancy of more than 11 atoms per $\mathrm{nm}^{2}$. This value is unrealistic and indicates clearly that additional processes such as (co-)precipitation and/or surface precipitation must have occurred during their experiments. The same conclusion can be made for the data of Yang et al. (2010), who reported similar data for $\mathrm{Pb}$ retention on a Na-bentonite from Lin'an (from China) at different ionic strength (0.001-0.1) with different background electrolytes and initial $\mathrm{Pb}$ concentration of $72.5 \mu \mathrm{M}$. Why such processes occurred in their experiments and not in the experiments of this study or those of Akafia et al. (2011) remains unclear. Based on extended X-ray absorption fluorescence spectroscopy measurements (EXAFS), Strawn and Sparks (1999) suggested the presence of $\mathrm{Pb}-\mathrm{Pb}$ dimer on montmorillonite because of surface multilayer adsorption and/or enhanced polymer formation due to nucleation from the clay. Surface precipitation of divalent metals on clay mineral surfaces has been repeatedly observed with spectroscopic techniques, especially with polarized EXAFS (P-EXAFS) (Scheidegger et al. 2001, Schlegel et al. 2001, DÃahn et al. 2002, Schlegel and Manceau 2006). Polynuclear Pb species also formed at pH's above 4.5 in the presence of high total $\mathrm{Pb}$ concentration sorbed on amorphous silica, a mineral impurity that is frequently present in montmorillonite samples (Elzinga and Sparks 2002). Therefore, the formation of polynuclear $\mathrm{Pb}$ species at the surfaces of clay minerals or of mineral impurities may explain the results from Yang et al. (2010), and Xu et al. (2008).

573 The data from Gu et al. (2010) onto Na-montmorillonite could only be fitted with an increase 574 of the site density from 0.01 to $0.05 \mathrm{~mol} \cdot \mathrm{kg}^{-1}$ (Figure S-4). It is unclear if this increase in site density may be justified or not: this site density corresponds to an edge specific surface area of $\sim 30-40 \mathrm{~m}^{2} \cdot \mathrm{g}^{-1}$ according to the calculations explained above. Gu et al. (2010) used the <2 $\mu \mathrm{m}$ fraction of an Upton (Wyoming, USA) montmorillonite, and applied an acid treatment at $\mathrm{pH} 3$ for $5 \mathrm{~h}$. This acid treatment could have formed new edge adsorption sites following the 580 However, such a sample preparation effect was not apparent in the study carried out on 581 Fithian illite by the same authors and with the same sample preparation procedure (Gu and 582 Evans 2007).

583 According to crystallographic data, clay mineral edge surfaces can adsorb a maximum $\mathrm{Pb}$ 584 monomer density of $d_{\text {mono }}=2$ atom; $\mathrm{nm}^{-2}$ (Tournassat et al. 2018). Above this threshold value, 
585 the presence of $\mathrm{Pb}$ dimers, polymers, or (co-)precipitation at the surface or in solution is 586 necessary to explain $\mathrm{Pb}$ retention values. $\mathrm{SCM}$, for which only $\mathrm{Pb}$ monomer adsorption 587 reactions are considered, should then be restricted to the interpretation of data that do not 588 exceed this threshold value. The value of the edge specific surface area is however not well 589 known for most of the investigated clay minerals. This value is also subject to variability 590 because of the origin of the clay stock and/or on the clay preparation procedure. The specific 591 surface area measured by BET cannot help to determine the specific surface area of edges. It 592 is however possible to quantify a minimal edge specific surface area $\left(E S S A_{\min }\right.$ in $\left.\mathrm{m}^{2} \cdot \mathrm{g}^{-1}\right)$ that 593 is necessary to explain the data according to:

$$
E S S A_{\min }=\frac{C_{a d s} \cdot N_{A}}{1000 \cdot d_{m o n o} \cdot 10^{18}}
$$

594 where $\mathrm{N}_{\mathrm{A}}$ is the Avogadro number $\left(6.022 \cdot 10^{23} \mathrm{~mol}^{-1}\right)$. If $E S S A_{\min }$ exceeds the maximum 595 reported value of edge specific surface area (i.e. $25 \mathrm{~m}^{2} \cdot \mathrm{g}^{-1}$ for montmorillonite), or the BET 596 surface area value (which always exceeds the edge specific surface area) in the presence of 597 conditions where only surface complexation is expected, i.e. high electrolyte background 598 concentration to minimize cation exchange and $\mathrm{pH}<6.5$ to prevent hydrocerussite 599 precipitation, then it can be concluded that the data are not representative of surface 600 complexation processes.

601 

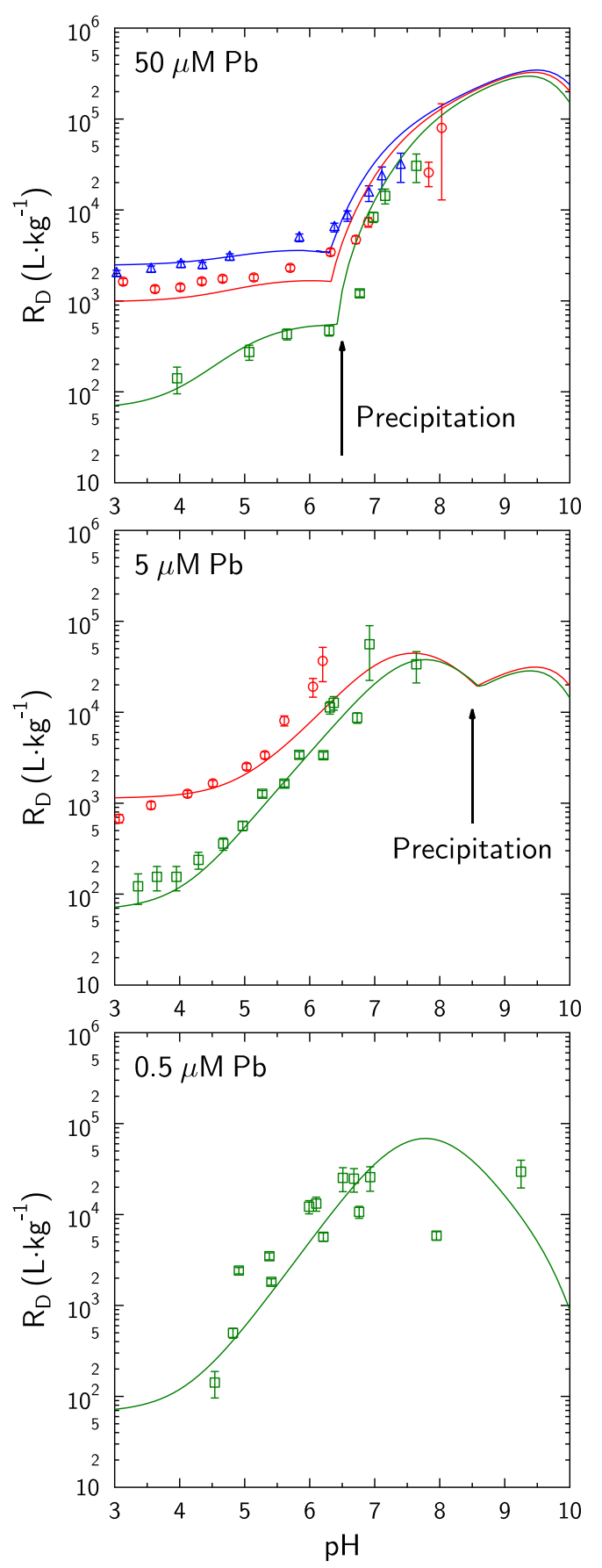

603 Figure 8. Prediction (lines) of the $\mathrm{Pb}$ adsorption data (symbols) on Swy-2 montmorillonite 604 from Akafia et al. (2011), in the presence of a guessed DIC concentration of $0.25 \mathrm{mM}$, and of 605 a guessed $\mathrm{Mg}$ concentration of $0.1 \mathrm{mM}$. Solid/ liquid ratio: $0.5 \mathrm{~g} \cdot \mathrm{L}^{-1}$. From top to bottom, $\mathrm{Pb}$ 606 total concentration of $50 \mu \mathrm{M}, 5 \mu \mathrm{M}$ and $0.5 \mu \mathrm{M}$. Blue triangles and line: $0.001 \mathrm{M} \mathrm{NaNO}_{3}$ 607 background electrolyte. Red circles and lines: $0.02 \mathrm{M} \mathrm{NaNO}_{3}$ background electrolyte. Green 608 squares and lines: $0.1 \mathrm{M} \mathrm{NaNO}_{3}$ background electrolyte. Error bands were calculated based 609 on a digitization error of $\pm 1 \%$ on the adsorbed $\mathrm{Pb}$ percentage (original data were reported as 610 percentage of adsorption vs. $\mathrm{pH}$ ). Data with error bands larger than their corresponding $\mathrm{R}_{\mathrm{D}}$ 611 value were discarded. 


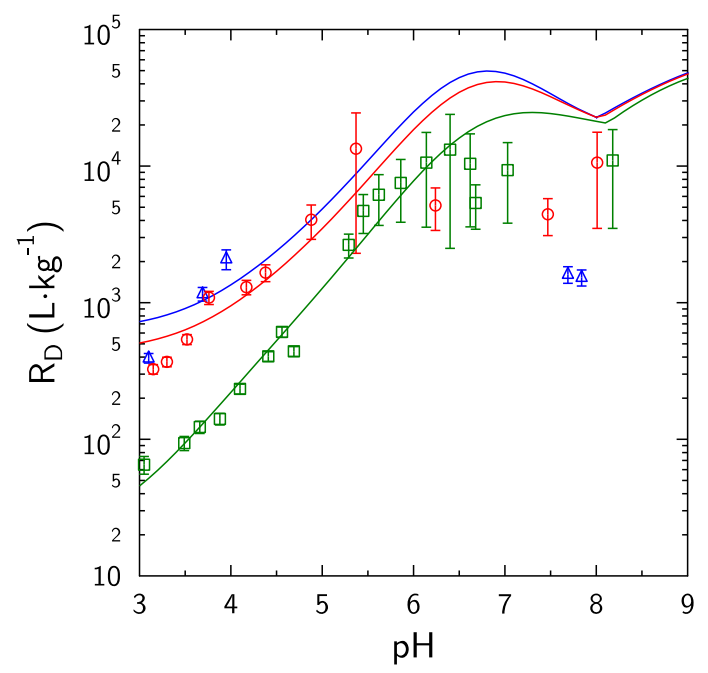

612

613 Figure 9. Prediction (lines) of the $\mathrm{Pb}$ adsorption data (symbols) on Fithian illite from $\mathrm{Gu}$ and 614 Evans (2007), in the presence of a guessed DIC concentration of $0.25 \mathrm{mM}$, and of a guessed $615 \mathrm{Mg}$ concentration of $0.1 \mathrm{mM}$. Solid/liquid ratio: $2.97 \mathrm{~g} \cdot \mathrm{L}^{-1} . \mathrm{Pb}$ total concentration $=50 \mu \mathrm{M}$. 616 The site density was reduced to $0.025 \mathrm{~mol} \cdot \mathrm{kg}^{-1}$ instead of $0.035 \mathrm{~mol} \cdot \mathrm{kg}^{-1}$. Blue triangles and 617 line: $0.001 \mathrm{M} \mathrm{NaNO}$ background electrolyte. Red circles and lines: $0.01 \mathrm{M} \mathrm{NaNO}$ 618 background electrolyte. Green squares and lines: $0.1 \mathrm{M} \mathrm{NaNO}_{3}$ background electrolyte. Error 619 bands were calculated based on a digitization error of $\pm 1 \%$ on the adsorbed $\mathrm{Pb}$ percentage 620 (original data were reported as percentage of adsorption vs. $\mathrm{pH}$ ). Data with error bands larger 621 than their corresponding $\mathrm{R}_{\mathrm{D}}$ value were discarded.

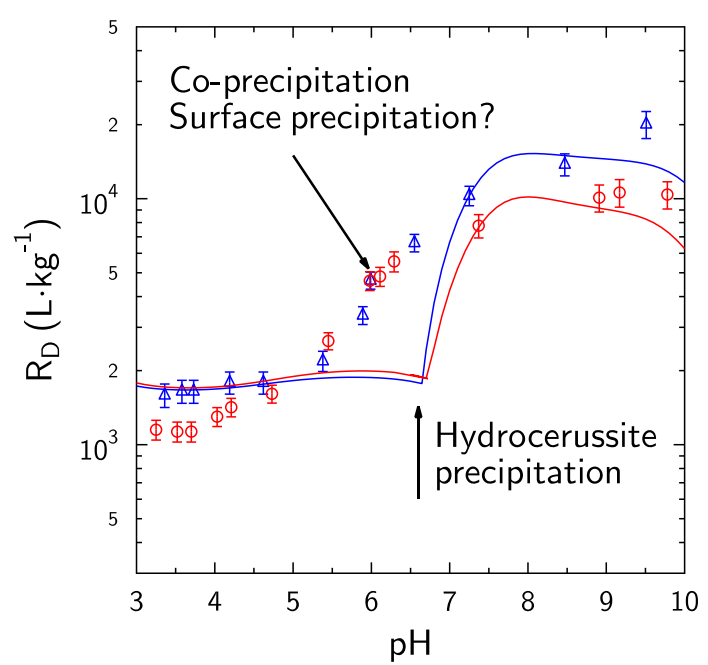

622

623 Figure 10. Comparison of this model prediction with the data from Xu et al. (2008) on MX-80 624 bentonite at $\mathrm{I}=0.01 \mathrm{M} \mathrm{NaNO}_{3}$. The initial DIC concentration was adjusted at $0.02 \mathrm{mM}$ to fit 625 the data at high $\mathrm{pH}$. Total $\mathrm{Pb}$ concentration was $48.3 \mu \mathrm{M}$. Blue triangles and line: data 626 obtained with a solid/liquid ratio of $0.2 \mathrm{~g} \cdot \mathrm{L}^{-1}$. Red circles and line: data obtained with a $627 \mathrm{solid} /$ liquid ratio of $0.4 \mathrm{~g} \cdot \mathrm{L}^{-1}$. Error bands were calculated based on a digitization error of $\pm 1 \%$ 628 on the adsorbed $\mathrm{Pb}$ percentage (original data were reported as percentage of adsorption vs. $629 \mathrm{pH})$. 


\section{Conclusion}

631 The determination of surface complexation model (SCM) parameters for direct or indirect use 632 in performance assessment calculations must be based on a critical review of the data 633 published in the literature. In this study, the experiments showed that many experimental 634 artifacts lead to misinterpretations of the processes underlying the measured $R_{D}$ values. For 635 example, the order of reagent addition can influence the result. In addition, correct 636 interpretation of the data can be impeded by side reactions such as precipitation in the 637 presence of carbonated species in solution. Dissolved inorganic carbon concentrations are 638 seldom reported in the literature. This study revealed that most of the $\mathrm{Pb}$ adsorption data 639 measured at $\mathrm{pH}$ above 6.5 may indeed be representative of precipitating $\mathrm{Pb}$ carbonate 640 minerals (see data from Akafia et al. (2011) on Figure 8). This problem can be circumvented 641 by using low initial $\mathrm{Pb}$ concentration (typically below $(5 \mu \mathrm{M})$ so that hydrocerussite is not 642 saturated in the investigated $\mathrm{pH}$ range. Unfortunately, only a small set of published data were 643 obtained with initial $\mathrm{Pb}$ concentration below $5 \mu \mathrm{M}$. Most of them had total $\mathrm{Pb}$ concentration 644 greater than or equal to $50 \mu \mathrm{M}$. In these conditions, the possible presence of surface 645 polymerization/(co-)precipitation processes were highlighted. Inadequate experimental 646 procedures can be detrimental to quantitative interpretations with SCM and thus, many $\mathrm{Pb}$ 647 retention data that are published in the literature should not be used to calibrate SCM 648 parameters, because these data may not be representative of a true adsorption equilibrium, but 649 rather of (co-)precipitation or surface precipitation in conditions that can be barely met in a 650 waste storage environment (e.g. data from Xu et al. (2008) and some data of Akafia et al. 651 (2011)). This conclusion could be certainly extended to other divalent metallic cations for 652 which precipitation in the presence of carbonate in solution has not been considered. The 653 determination of surface complexation model parameters for PA should rely on preliminary 654 building of an adequate adsorption database, where adequate means that all experimental 655 conditions are met to quantify surface complexation only.

\section{Acknowledgement}

657 This work was supported by the French Radioactive Waste Management Agency (Andra) as 658 part of the Andra-BRGM scientific partnership (CTEC project). We gratefully acknowledge 659 Prof. Tsutomu Sato from Hokkaido University for providing the Kunipia-P sample and PSI660 LES laboratory for providing the IdP sample. 
Supplementary information to this article can be found online. Supplementary information contains Figures S-1 to S-4 and the experimental data in 26 tables.

\section{References:}

Akafia, M. M., T. J. Reich, and C. M. Koretsky. 2011. Assessing Cd, Co, Cu, Ni, and Pb Sorption on montmorillonite using surface complexation models. Applied Geochemistry 26:S154 - S157.

Altmann, S. 2008. Geo'chemical research: A key building block for nuclear waste disposal safety cases. Journal of Contaminant Hydrology 102:174-179.

Altmann, S., C. Tournassat, F. Goutelard, J.-C. Parneix, T. Gimmi, and N. Maes. 2012. Diffusion-driven transport in clayrock formations. Applied Geochemistry 27:463-478.

Armitage, P. J., D. R. Faulkner, and R. H. Worden. 2013. Caprock corrosion. Nature Geoscience 6:79-80.

Baeyens, B., and M. H. Bradbury. 1995. A quantitative mechanistic description of Ni, Zn and Ca sorption on Na-montmorillonite. Part I: Physico-chemical characterisation and titration measurements. . Paul Scherrer Institut (PSI), Villigen.

Baeyens, B., and M. H. Bradbury. 1997. A mechanistic description of Ni and Zn sorption on Na-montmorillonite. Part I: Titration and sorption measurements. Journal of Contaminant Hydrology 27:199-222.

Barbier, F., G. Duc, and M. Petit-Ramel. 2000. Adsorption of lead and cadmium ions from aqueous solution to the montmorillonite/water interface. Colloids and Surfaces APhysicochemical and Engineering Aspects 166:153-159.

Beaucaire, C., E. Tertre, E. Ferrage, B. Grenut, S. Pronier, and B. Madé. 2012. A thermodynamic model for the prediction of pore water composition of clayey rock at 25 and $80{ }^{\circ} \mathrm{C}$ - Comparison with results from hydrothermal alteration experiments. Chemical Geology 334:62-76.

Borisover, M., and J. A. Davis. 2015. Chapter 2 - Adsorption of inorganic and organic solutes by clay minerals. Pages 33-70 in C. Tournassat, C. I. Steefel, I. C. Bourg, and F. Bergaya, editors. Natural and Engineered Clay Barriers. . Elsevier.

Bourg, I. C., G. Sposito, and A. C. M. Bourg. 2007. Modeling the acid-base surface chemistry of montmorillonite. Journal of Colloid and Interface Science 312:297-310.

Bradbury, M. H., and B. Baeyens. 1997. A mechanistic description of Ni and Zn sorption on Na-montmorillonite. Part II: modeling. Journal of Contaminant Hydrology 27:223248.

Bradbury, M. H., and B. Baeyens. 2000. A generalised sorption model for the concentration dependent uptake of caesium by argillaceous rocksbae. Journal of Contaminant Hydrology 42:141-163.

Bradbury, M. H., and B. Baeyens. 2002. Porewater Chemistry in Compacted Re-Saturated MX-80 Bentonite: Physico-Chemical Characterisation and Geochemical Modelling.

Bradbury, M. H., and B. Baeyens. 2005a. Modelling the sorption of $\mathrm{Mn}(\mathrm{II}), \mathrm{Co}(\mathrm{II}), \mathrm{Ni}(\mathrm{II})$, $\mathrm{Zn}(\mathrm{II}), \mathrm{Cd}(\mathrm{II}), \mathrm{Eu}(\mathrm{III}), \mathrm{Am}(\mathrm{III}), \mathrm{Sn}(\mathrm{IV}), \mathrm{Th}(\mathrm{IV}), \mathrm{Np}(\mathrm{V})$ and U(VI) on montmorillonite: Linear free energy relationships and estimates of surface binding constants for some selected heavy metals and actinides. Geochimica et Cosmochimica Acta 69:875-892. 
Bradbury, M. H., and B. Baeyens. 2005b. Experimental and modelling investigations on Naillite: Acid-base behaviour and the sorption of strontium, nickel, europium and uranyl. . Nagra, National Cooperative for the Disposal of Radioactive Waste.

Busch, A., S. Alles, Y. Gensterblum, D. Prinz, D. N. Dewhurst, M. D. Raven, H. Stanjek, and B. M. Krooss. 2008. Carbon dioxide storage potential of shales. International Journal of Greenhouse Gas Control 2:297-308.

Chang, F. R. C., and G. Sposito. 1996. The electrical double layer of a disked-shaped clay mineral particle: effect of electrolyte properties and surface charge density. Journal of Colloid and Interface Science 178:555-564.

Chapman, N., and A. Hooper. 2012. The disposal of radioactive wastes underground. Proceedings of the Geologists' Association 123:46-63.

Charlet, L., and C. Tournassat. 2005. Fe(II)-Na(I)-Ca(II) cation exchange on montmorillonite in chloride medium; evidence for preferential clay adsorption of chloride â€" metal ion pairs in seawater. Aquatic Geochemistry 11:115-137.

Chen, Z., G. Montavon, Z. Guo, X. Wang, S. Razafindratsima, J.-C. Robinet, and C. Landesman. 2014a. Approaches to surface complexation modeling of $\mathrm{Ni}$ (II) on Callovo-Oxfordian clayrock. Applied Clay Science 101:369-380.

Chen, Z., G. Montavon, S. Ribet, Z. Guo, J.-C. Robinet, K. David, C. Tournassat, B. Grambow, and C. Landesman. 2014b. Key factors to understand in-situ behavior of Cs in Callovo-Oxfordian clay-rock (France). Chemical Geology 387:47-58.

DÃahn, R., A. M. Scheidegger, A. Manceau, M. Schlegel, B. Baeyens, M. H. Bradbury, and M. schl. Morales. 2002. Neoformation of $\mathrm{Ni}$ phyllosilicate upon $\mathrm{Ni}$ uptake on montmorillonite: a kinetics study by powder and polarized extended X-ray absorption fine structure spectroscopy. Geochimica et Cosmochimica Acta 66:2335-2347.

Davis, J. A., J. A. Coston, D. B. Kent, and C. C. Fuller. 1998. Application of the surface complexation concept to complex mineral assemblages. Environmental Science and Technology 32:2820-2828.

Davis, J. A., and D. Kent. 1990. Surface complexation modeling in aqueous geochemistry. Reviews in Mineralogy and Geochemistry 23:177-260.

Davis, J. A., D. E. Meece, M. Kohler, and G. P. Curtis. 2004. Approaches to surface complexation modeling of Uranium(VI) adsorption on aquifer sediments. Geochimica et Cosmochimica Acta 68:3621-3641.

Druteikien, R., J. Šapolait, Ž. Ežerinskis, and L. Juodis. 2017. Batch-type study of Cs, Co, and Tc binding with hydrated cement under hyperalkaline conditions. Journal of Radioanalytical and Nuclear Chemistry:1-9.

Duc, M., F. Gaboriaud, and F. Thomas. 2005. Sensitivity of the acid-base properties of clays to the methods of preparation and measurement: 1. Literature review. Journal of Colloid and Interface Science 289:139-147.

Dzombak, D. A., and F. M. M. Morel. 1990. Surface complexation modeling-Hydrous ferric oxide. Page 393. . New York.

Echeverría, J. C., I. Zarranz, J. Estella, and J. J. Garrido. 2005. Simultaneous effect of pH, temperature, ionic strength, and initial concentration on the retention of lead on illite. Applied Clay Science 30:103-115.

Elzinga, E. J., and D. L. Sparks. 2002. X-ray absorption spectroscopy study of the effects of $\mathrm{pH}$ and ionic strength on $\mathrm{Pb}$ (II) sorption to amorphous silica. Environmental science \& technology 36:4352-4357.

Fletcher, P., and G. Sposito. 1989. The chemical modeling of clay/electrolyte interactions for montmorillonite. Clay Minerals 24:375-391. 
Le Forestier, L., F. Muller, F. Villiéras, and M. Pelletier. 2010. Textural and hydration properties of a synthetic montmorillonite compared with a natural $\mathrm{Na}$-exchanged clay analogue. Applied Clay Science 48:18-25.

Gaboreau, S., F. Claret, C. Crouzet, E. Giffaut, and C. Tournassat. 2012. Caesium uptake by Callovian-Oxfordian clayrock under alkaline perturbation. Applied Geochemistry 27:1194-1201.

Gaboreau, S., J.-C. Robinet, and D. Prêt. 2016. Optimization of pore network characterization of compacted clay materials by TEM and FIB/SEM imaging. Microporous and Mesoporous Materials 224:116-128.

Gailhanou, H., C. Lerouge, M. Debure, S. Gaboreau, E. C. Gaucher, S. Grangeon, J.-M. Grenèche, M. Kars, B. Madé, N. C. M. Marty, F. Warmont, and C. Tournassat. 2017. Effects of a thermal perturbation on mineralogy and pore water composition in a clayrock: an experimental and modeling study. Geochimica et Cosmochimica Acta 197:193-214.

Gailhanou, H., J. C. van Miltenburg, J. Rogez, J. Olives, M. Amouric, E. C. Gaucher, and P. Blanc. 2007. Thermodynamic properties of anhydrous smectite MX-80, illite IMt-2 and mixed-layer illite-smectite ISCz-1 as determined by calorimetric methods. Part I: Heat capacities, heat contents and entropies. Geochimica et Cosmochimica Acta 71:5463-5473.

Gaucher, E., C. Robelin, J.-M. Matray, G. Negrel, Y. Gros, J. F. Heitz, A. Vinsot, H. Rebours, A. Cassabagnere, and A. Bouchet. 2004. ANDRA underground research laboratory: Interpretation of the mineralogical and geochemical data acquired in the CallovianOxfordian Formation by investigative drilling. Physics and Chemistry of the Earth, Parts A/B/C 29:55-77.

Giffaut, E., M. Grivé, P. Blanc, P. Vieillard, E. Colàs, H. Gailhanou, S. Gaboreau, N. Marty, B. Madé, and L. Duro. 2014. Andra thermodynamic database for performance assessment: ThermoChimie. Applied Geochemistry 49:225-236.

Goldberg, S. 2013. Surface complexation modeling. Reference Module in Earth Systems and Environmental Sciences, Elsevier.

Grangeon, S., A. Vinsot, C. Tournassat, C. Lerouge, E. Giffaut, S. Heck, N. Groschopf, M. A. Denecke, S. Wechner, and T. Schäfer. 2015. The influence of natural trace element distribution on the mobility of radionuclides. The exemple of nickel in a clay-rock. Applied Geochemistry 52:155-173.

$\mathrm{Gu}, \mathrm{X}$., and L. J. Evans. 2007. Modelling the adsorption of $\mathrm{Cd}(\mathrm{II}), \mathrm{Cu}(\mathrm{II}), \mathrm{Ni}(\mathrm{II}), \mathrm{Pb}(\mathrm{II})$, and $\mathrm{Zn}$ (II) onto Fithian illite. Journal of Colloid and Interface Science 307:317-325.

Gu, X. Y., L. J. Evans, and S. J. Barabash. 2010. Modeling the adsorption of Cd (II), Cu (II), $\mathrm{Ni}$ (II), Pb (II) and $\mathrm{Zn}$ (II) onto montmorillonite. Geochimica et Cosmochimica Acta $74: 5718-5728$.

Hiemstra, T., and W. H. Van Riemsdijk. 1996. A surface structural approach to ion adsorption: the charge distribution (CD) model. Journal of Colloid and Interface Science 179:488-508.

Ikhsan, J., J. D. Wells, B. B. Johnson, and M. J. Angove. 2005. Surface complexation modeling of the sorption of $\mathrm{Zn}$ (II) by montmorillonite. Colloids and Surfaces APhysicochemical and Engineering Aspects 252:33-41.

Jackson, M. L. 1975. Soil chemical analysis - advanced course 2nd edition. . Published by the author, University of Wisconsin, Madison, Wisconsin.

Kinniburgh, D., and D. Cooper. 2011. PhreePlot: Creating graphical output with PHREEQC.

Marani, D., G. Macchi, and M. Pagano. 1995. Lead precipitation in the presence of sulphate and carbonate: Testing of thermodynamic predictions. Water Research 29:1085-1092. 
Marcussen, H., P. E. Holm, B. W. Strobel, and H. C. B. Hansen. 2009. Nickel sorption to goethite and montmorillonite in presence of citrate. Environmental Science \& Technology 43:1122-1127.

Marques Fernandes, M., A. Scheinost, and B. Baeyens. 2016. Sorption of trivalent lanthanides and actinides onto montmorillonite: Macroscopic, thermodynamic and structural evidence for ternary hydroxo and carbonato surface complexes on multiple sorption sites. Water Research 99:74-82.

Marques Fernandes, M., N. Ver, and B. Baeyens. 2015. Predicting the uptake of Cs, Co, Ni, $\mathrm{Eu}, \mathrm{Th}$ and $\mathrm{U}$ on argillaceous rocks using sorption models for illite. Applied Geochemistry 59:189-199.

Marty, N. C. M., J. Cama, T. Sato, D. Chino, F. Villiéras, A. Razafitianamaharavo, J. Brendlé, E. Giffaut, J. M. Soler, E. C. Gaucher, and C. Tournassat. 2011. Dissolution kinetics of synthetic Na-smectite. An integrated experimental approach. Geochimica et Cosmochimica Acta 75:5849-5864.

Metz, V., H. Raanan, H. Pieper, D. Bosbach, and J. Ganor. 2005. Towards the establishment of a reliable proxy for the reactive surface area of smectite. Geochimica et Cosmochimica Acta 69:2581-2591.

Neuzil, C. E. 2013. Can shale safely host US nuclear waste? Eos, Transactions American Geophysical Union 94:261-262.

Parkhurst, D. L., and C. A. J. Appelo. 2013. Description of Input and Examples for PHREEQC Version 3-a Computer Program for Speciation, Batch-reaction, Onedimensional Transport, and Inverse Geochemical Calculations.

Richter, A., V. Brendler, C. Nebelung, T. E. Payne, and T. Brasser. 2009. Sorption Databases for Increasing Confidence in Performance Assessment. Pages 361-367 ASME 2009 12th International Conference on Environmental Remediation and Radioactive Waste Management. . American Society of Mechanical Engineers.

Scheidegger, A., R. Dahn, A. Manceau, M. Schlegel, B. Baeyens, and M. H. Bradbury. 2001. Ni clay neoformation on montmorillonite surface. Journal of Synchrotron Radiation 8:533-535.

Schlegel, M. L., and A. Manceau. 2006. Evidence for the nucleation and epitaxial growth of Zn phyllosilicate on montmorillonite. Geochimica et Cosmochimica Acta 70:901-917.

Schlegel, M. L., A. Manceau, L. Charlet, D. L. Chateigner, and J. L. Hazemann. 2001. Sorption of metal ions on clay minerals. III. Nucleation and epitaxial growth of $\mathrm{Zn}$ phyllosilicate on the edges of hectorite. Geochimica et Cosmochimica Acta 65:41554470.

Secor, R. B., and C. J. Radke. 1985. Spillover of the diffuse double layer on montmorillonite particles. Journal of Colloid and Interface Science 103:237-244.

Sipos, P., T. Németh, V. K. Kis, and I. Mohai. 2008. Sorption of copper, zinc and lead on soil mineral phases. Chemosphere 73:461-469.

Sposito, G. 1984. The surface chemistry of soils. Page 223. . Oxford University Press, New York.

Stockmann, M., V. Brendler, J. Schikora, S. Britz, J. Flügge, and U. Noseck. 2012. Smart Kdconcept based on surface complexation modeling. Mineral. Mag 76:2412.

Strawn, D. G., and D. L. Sparks. 1999. The use of XAFS to distinguish between inner-and outer-sphere lead adsorption complexes on montmorillonite. Journal of Colloid and Interface Science 216:257-269.

Tachi, Y., and K. Yotsuji. 2014. Diffusion and sorption of $\mathrm{Cs}^{+}, \mathrm{Na}^{+}, \mathrm{I}^{-}$and $\mathrm{HTO}$ in compacted sodium montmorillonite as a function of porewater salinity: Integrated sorption and diffusion model. Geochimica et Cosmochimica Acta 132:75-93. 
Tertre, E., C. Beaucaire, N. Coreau, and A. Juery. 2009. Modelling Zn(II) sorption onto clayey sediments using a multi-site ion-exchange model. Applied Geochemistry 24:1852-1861.

Tertre, E., G. Berger, S. Castet, M. Loubet, and E. Giffaut. 2005. Experimental sorption of $\mathrm{Ni}^{2+}, \mathrm{Cs}^{+}$and $\mathrm{Ln}^{3+}$ onto a montmorillonite up to 150ẹgreC. Geochimica et Cosmochimica Acta 69:4937-4948.

Tournassat, C., M. Bizi, G. Braibant, and C. Crouzet. 2011. Influence of montmorillonite tactoid size on $\mathrm{Na}-\mathrm{Ca}$ cation exchange reactions. Journal of Colloid and Interface Science 364:443-454.

Tournassat, C., I. C. Bourg, C. I. Steefel, and F. Bergaya. 2015. Chapter 1 - Surface Properties of Clay Minerals. Pages 5-31 in C. Tournassat, C. I. Steefel, I. C. Bourg, and F. Bergaya, editors. Natural and Engineered Clay Barriers. . Elsevier.

Tournassat, C., J. A. Davis, C. Chiaberge, S. Grangeon, and I. C. Bourg. 2016. Modeling the acid-base properties of montmorillonite edge surfaces. Environmental Science \& Technology 50:13436-13445.

Tournassat, C., H. Gailhanou, C. Crouzet, G. Braibant, A. Gautier, and E. C. Gaucher. 2009. Cation exchange selectivity coefficient values on smectite and mixed-layer illite/smectite minerals. Soil Science Society of America Journal 73:928-942.

Tournassat, C., H. Gailhanou, C. Crouzet, G. Braibant, A. Gautier, A. Lassin, P. Blanc, and E. C. Gaucher. 2007. Two cation exchange models for direct and inverse modelling of solution major cation composition in equilibrium with illite surfaces. Geochimica et Cosmochimica Acta 71:1098-1114.

Tournassat, C., S. Grangeon, P. Leroy, and E. Giffaut. 2013. Modeling specific pH dependent sorption of divalent metals on montmorillonite surfaces. A review of pitfalls, recent achievements and current challenges. American Journal of Science 313:395-451.

Tournassat, C., R. M. Tinnacher, S. Grangeon, and J. A. Davis. 2018. Modeling uranium (VI) adsorption onto montmorillonite under varying carbonate concentrations: A surface complexation model accounting for the spillover effect on surface potential. Geochimica et Cosmochimica Acta:291-308.

Turner, D. R., R. T. Pabalan, and F. P. Bertetti. 1998. Neptunium(V) sorption on montmorillonite: an experimental and surface complexation modeling study. Clays and Clay Minerals 46:256-269.

Xu, D., X. L. Tan, C. L. Chen, and X. K. Wang. 2008. Adsorption of Pb(II) from aqueous solution to MX-80 bentonite: Effect of $\mathrm{pH}$, ionic strength, foreign ions and temperature. Applied Clay Science 41:37-46.

Yang, S., D. Zhao, H. Zhang, S. Lu, and X. L. andYu Chen. 2010. Impact of environmental conditions on the sorption behavior of $\mathrm{Pb}$ (II) in $\mathrm{Na}$-bentonite suspensions. Journal of hazardous materials 183.

Yokoyama, S., M. Kuroda, and T. Sato. 2005. Atomic force microscopy study of montmorillonite dissolution under highly alkaline conditions. Clays and Clay Minerals 53:147-154.

Zachara, J. M., and S. C. Smith. 1994. Edge complexation reactions of cadmium on specimen and soil-derived smectite. Soil Science Society of America Journal 58:762-769. 


\section{Highlights:}

- Retention of $\mathrm{Pb}^{2+}$ on clay mineral surfaces was modeled with a simple surface complexation model.

- Model calibration requires experimental data in well-defined and well-controlled conditions.

- All experimental conditions are met to quantify surface complexation only

- Experimental artifacts, especially the presence of carbonate in solution, cause misinterpretation of measured retention values.

- Fully controlled experimental conditions are necessary for calibrating models for performance assessment studies. 
Click here to download Table: Table 1.docx

\begin{tabular}{lllll}
\hline $\begin{array}{c}\text { Initial } \mathrm{Pb} \\
\text { concentration } \\
(\mu \mathrm{M})\end{array}$ & $\mathrm{R}_{\mathrm{SL}}\left(\mathrm{g} \cdot \mathrm{L}^{-1}\right)$ & $\begin{array}{l}\mathrm{NaCl} \\
\text { concentration } \\
(\mathrm{M})\end{array}$ & $\mathrm{pH}$ range & $\mathrm{T}\left({ }^{\circ} \mathrm{C}\right)$ \\
\hline 1 & 1 & 0.1 & $3-9$ & $20^{*}$ \\
10 & 1 & 0.1 & $3-9$ & $20^{*}$ \\
50 & 1 & 0.1 & $3-9$ & $20^{*}$ \\
1 & 0.5 & 0.025 & $3-9$ & $20^{*}$ \\
1 & 1 & 0.1 & $3-7$ & 67 \\
\hline
\end{tabular}

* Room temperature 
Montmorillonite Illite

Cation exchange

$\mathrm{CEC}\left(\mathrm{X}^{-}\right.$site density) in $\mathrm{mol} \cdot \mathrm{kg}^{-1}$

$0.78^{(1)} \quad 0.2^{(2)}$

Reactions $\log \mathrm{K}$

$2 \mathrm{XNa}+\mathrm{Pb}^{2+}=\mathrm{X}_{2} \mathrm{~Pb}+2 \mathrm{Na}^{+}$

$0.6(0.9)$

$0.7(0.9)$

$2 \mathrm{XNa}+\mathrm{Mg}^{2+}=\mathrm{X}_{2} \mathrm{Mg}+2 \mathrm{Na}^{+}$

0.6

0.7

$2 \mathrm{XNa}+\mathrm{Ca}^{2+}=\mathrm{X}_{2} \mathrm{Ca}+2 \mathrm{Na}^{+}$

0.5

0.5

Edge surface complexation

\begin{tabular}{lll}
\hline Site density $(>\mathrm{S})$ in $\mathrm{mol} \cdot \mathrm{kg}^{-1}$ & 0.01 & 0.035 \\
\hline Reactions & $\log \mathrm{K}$ & -6.6 \\
$>\mathrm{SOH}=>\mathrm{SO}^{-}+\mathrm{H}^{+}$ & -8.1 & \\
& & $0.6(0.9)$ \\
$>\mathrm{SOH}+\mathrm{Pb}^{2+}=>\mathrm{SOPb}^{+}+\mathrm{H}^{+}$ & $0(0.2)$ & $-7.2(-6.7)$ \\
$>\mathrm{SOH}+\mathrm{Pb}^{2+}+\mathrm{H}_{2} \mathrm{O}=>\mathrm{SOPb}(\mathrm{OH})+2 \mathrm{H}^{+}$ & Not necessary & \\
& & \\
& & \\
(1) $($Bradbury and Baeyens 2002$)$ & & \\
(2) $($ Bradbury and Baeyens 2000$)$ &
\end{tabular}


Click here to download Table: Table 3.docx

\begin{tabular}{|c|c|c|c|c|c|c|}
\hline Clay Type & $\begin{array}{c}\text { Clay material } \\
\text { preparation } \\
\text { procedure }\end{array}$ & $\mathrm{pH}$ & $\begin{array}{l}\text { Background } \\
\text { electrolyte } \\
\text { (M) }\end{array}$ & $\begin{array}{l}{[\mathrm{Pb}]_{\mathrm{tot}}} \\
(\mu \mathrm{M})\end{array}$ & $\begin{array}{c}\mathrm{R}_{\mathrm{SL}} \\
\left(\mathrm{g} \cdot \mathrm{L}^{-1}\right)\end{array}$ & Reference \\
\hline SWy-2 Mont. & None & $3-11$ & $\begin{array}{c}0.001-0.1 \\
\mathrm{NaNO}_{3}\end{array}$ & $0.1-50$ & 0.5 & (Akafia et al. 2011) \\
\hline Fithian illite & $\begin{array}{c}<2 \mu \mathrm{m} \\
\mathrm{NaNO}_{3} \text { treated }\end{array}$ & $3-8$ & $\begin{array}{c}0.001-0.1 \\
\mathrm{NaNO}_{3}\end{array}$ & 50 & 2.97 & $\begin{array}{c}\text { (Gu and Evans } \\
\text { 2007) }\end{array}$ \\
\hline MX-80 Mont & None & $1-12$ & $0.01 \mathrm{NaNO}_{3}$ & 48.3 & $0.2 ; 0.4$ & (Xu et al. 2008) \\
\hline $\begin{array}{c}\text { Wyoming } \\
\text { Mont. }\end{array}$ & $\begin{array}{c}<2 \mu \mathrm{m} \\
\mathrm{NaNO}_{3} \text { treated }\end{array}$ & 3- 9 & $\begin{array}{c}0.0010 .1 \\
\mathrm{NaNO}_{3}\end{array}$ & 48.8 & 1.5 & (Gu et al. 2010) \\
\hline $\begin{array}{l}\text { Chinese } \\
\text { bentonite }\end{array}$ & $\begin{array}{c}<2 \mu \mathrm{M} \\
\begin{array}{c}1.0 \mathrm{M} \mathrm{NaCl} \\
\text { treated }\end{array}\end{array}$ & $2-12$ & $\begin{array}{c}0.001-0.1 \\
\mathrm{NaClO} 4\end{array}$ & 72.5 & 0.5 & (Yang et al. 2010) \\
\hline
\end{tabular}




\section{List of Figure Captions}

Figure 1. Comparisons of experimental datasets for $\mathrm{Pb}$ retention at room temperature on $\mathrm{MX}$ 80, Kunipia-P, IdP and COx clay as a function of $\mathrm{pH}$, ionic strength $(0.025 \mathrm{M} \mathrm{NaCl}=$ closed symbols; $0.1 \mathrm{M} \mathrm{NaCl}=$ open symbols), and total $\mathrm{Pb}$ initial concentrations (triangle symbols: 1 $\mu \mathrm{M}$; circle symbols: $10 \mu \mathrm{M}$; square symbols: $50 \mu \mathrm{M}$ ) (Details of the datasets are given in supporting information file).

Figure 2. Comparison of $\mathrm{Pb}$ retention on MX-80 (triangles), Kunipia (diamonds), IdP (circles) and $\mathrm{COx}$ clay (squares) at room temperature as a function of $\mathrm{pH}$, in the presence of $0.1 \mathrm{M}$ $\mathrm{NaCl}$ background electrolyte and a total $\mathrm{Pb}$ concentration of $1 \mu \mathrm{M}$.

Figure 3. Pb retention on MX-80 (triangles), Kunipia (diamonds), IdP (circles) and COx clay (squares) at room temperature (open symbols) and $67^{\circ} \mathrm{C} \mathrm{(closed} \mathrm{symbols)} \mathrm{as} \mathrm{a} \mathrm{function} \mathrm{of} \mathrm{pH}$, in the presence of $0.1 \mathrm{M} \mathrm{NaCl}$ background electrolyte and a total $\mathrm{Pb}$ concentration of $1 \mu \mathrm{M}$ (Details of the datasets are given in supporting information file).

Figure 4. Top figure: $\mathrm{Pb}$ solid phase predominance as a function of $\mathrm{pH}$ and $\mathrm{pCO}_{2}$ in the absence of adsorption processes. Minerals allowed to precipitate: cerussite $\left(\mathrm{PbCO}_{3}\right)$, hydrocerussite $\left(\mathrm{Pb}_{3}\left(\mathrm{CO}_{3}\right)_{2}(\mathrm{OH})_{2}\right)$, cotunnite $\left(\mathrm{PbCl}_{2}\right)$, laurionite $(\mathrm{PbClOH})$, paralaurionite $(\mathrm{PbClOH})$ and $\mathrm{Pb}(\mathrm{OH})_{2}(\mathrm{~s})$ : Total $\mathrm{Pb}$ concentration: $50 \mu \mathrm{M}\left(\log [\mathrm{Pb}]_{\text {tot }}=-4.3\right)$. Middle figure: Contour plot of calculated $\mathrm{Pb}$ concentration in solution ( $\log _{10}$ scale) as a function of $\mathrm{pH}$ and $\mathrm{pCO}_{2}$. The color change between two contour lines indicates a change of $0.25 \log _{10}$ scale units. Bottom figure: Contour plot of calculated DIC concentration as a function of $\mathrm{pH}$ and $\mathrm{pCO}_{2}\left(\log _{10}\right.$ scale). Symbols correspond to experimental measurements in the presence (triangles) or absence (circles) of clay and with sample preparation in contact with atmosphere (white symbols) or in the glove-box (black symbols). The background electrolyte concentration is $0.1 \mathrm{M} \mathrm{NaCl}$ for all figures.

Figure 5. Modeling of $\mathrm{Pb}$ adsorption and precipitation at room temperature according to the parameters given in Table 2 for MX-80 (left) and illite (right).

Figure 6. Model prediction for Pb adsorption / precipitation on Kunipia-P (left) and COx clay (right) at room temperature. Model parameters for Kunipia-P are the same as for MX-80. Pb adsorption on COx clay was modeled with an illite surface contribution of $50 \%$ and a smectite surface (montmorillonite) contribution of $50 \%$.

Figure 7. Model predicting $\mathrm{Pb}$ adsorption on the four clay samples at $67^{\circ} \mathrm{C}$. Parameters are given in Table 2. Total $\mathrm{Pb}$ concentration: $1 \mu \mathrm{M}$. Solid/liquid ratio: $1 \mathrm{~g} \cdot \mathrm{L}^{-1}$. Background electrolyte: $\mathrm{NaCl} 0.1 \mathrm{M}$.

Figure 8. Prediction (lines) of the $\mathrm{Pb}$ adsorption data (symbols) on Swy-2 montmorillonite from Akafia et al. (2011), in the presence of a guessed DIC concentration of $0.25 \mathrm{mM}$, and of a guessed $\mathrm{Mg}$ concentration of $0.1 \mathrm{mM}$. Solid/ liquid ratio: $0.5 \mathrm{~g} \cdot \mathrm{L}^{-1}$. From top to bottom, $\mathrm{Pb}$ total concentration of $50 \mu \mathrm{M}, 5 \mu \mathrm{M}$ and $0.5 \mu \mathrm{M}$. Blue triangles and line: $0.001 \mathrm{M} \mathrm{NaNO}_{3}$ background electrolyte. Red circles and lines: $0.02 \mathrm{M} \mathrm{NaNO}_{3}$ background electrolyte. Green squares and lines: $0.1 \mathrm{M} \mathrm{NaNO}_{3}$ background electrolyte. Error bands were calculated based on a digitization error of $\pm 1 \%$ on the adsorbed $\mathrm{Pb}$ percentage (original data were reported as percentage of adsorption vs. $\mathrm{pH}$ ). Data with error bands larger than their corresponding $\mathrm{R}_{\mathrm{D}}$ value were discarded.

Figure 9. Prediction (lines) of the Pb adsorption data (symbols) on Fithian illite from $\mathrm{Gu}$ and Evans (2007), in the presence of a guessed DIC concentration of $0.25 \mathrm{mM}$, and of a guessed 
Mg concentration of $0.1 \mathrm{mM}$. Solid/liquid ratio: $2.97 \mathrm{~g} \cdot \mathrm{L}^{-1} . \mathrm{Pb}$ total concentration $=50 \mu \mathrm{M}$. The site density was reduced to $0.025 \mathrm{~mol} \cdot \mathrm{kg}^{-1}$ instead of $0.035 \mathrm{~mol} \cdot \mathrm{kg}^{-1}$. Blue triangles and line: $0.001 \mathrm{M} \mathrm{NaNO}$ background electrolyte. Red circles and lines: $0.01 \mathrm{M} \mathrm{NaNO}_{3}$ background electrolyte. Green squares and lines: $0.1 \mathrm{M} \mathrm{NaNO}_{3}$ background electrolyte. Error bands were calculated based on a digitization error of $\pm 1 \%$ on the adsorbed $\mathrm{Pb}$ percentage (original data were reported as percentage of adsorption vs. $\mathrm{pH}$ ). Data with error bands larger than their corresponding $\mathrm{R}_{\mathrm{D}}$ value were discarded.

Figure 10. Comparison of this model prediction with the data from $\mathrm{Xu}$ et al. (2008) on MX-80 bentonite at $\mathrm{I}=0.01 \mathrm{M} \mathrm{NaNO}_{3}$. The initial DIC concentration was adjusted at $0.02 \mathrm{mM}$ to fit the data at high $\mathrm{pH}$. Total $\mathrm{Pb}$ concentration was $48.3 \mu \mathrm{M}$. Blue triangles and line: data obtained with a solid/liquid ratio of $0.2 \mathrm{~g} \cdot \mathrm{L}^{-1}$. Red circles and line: data obtained with a solid/liquid ratio of $0.4 \mathrm{~g} \cdot \mathrm{L}^{-1}$. Error bands were calculated based on a digitization error of $\pm 1 \%$ on the adsorbed $\mathrm{Pb}$ percentage (original data were reported as percentage of adsorption vs. $\mathrm{pH})$. 

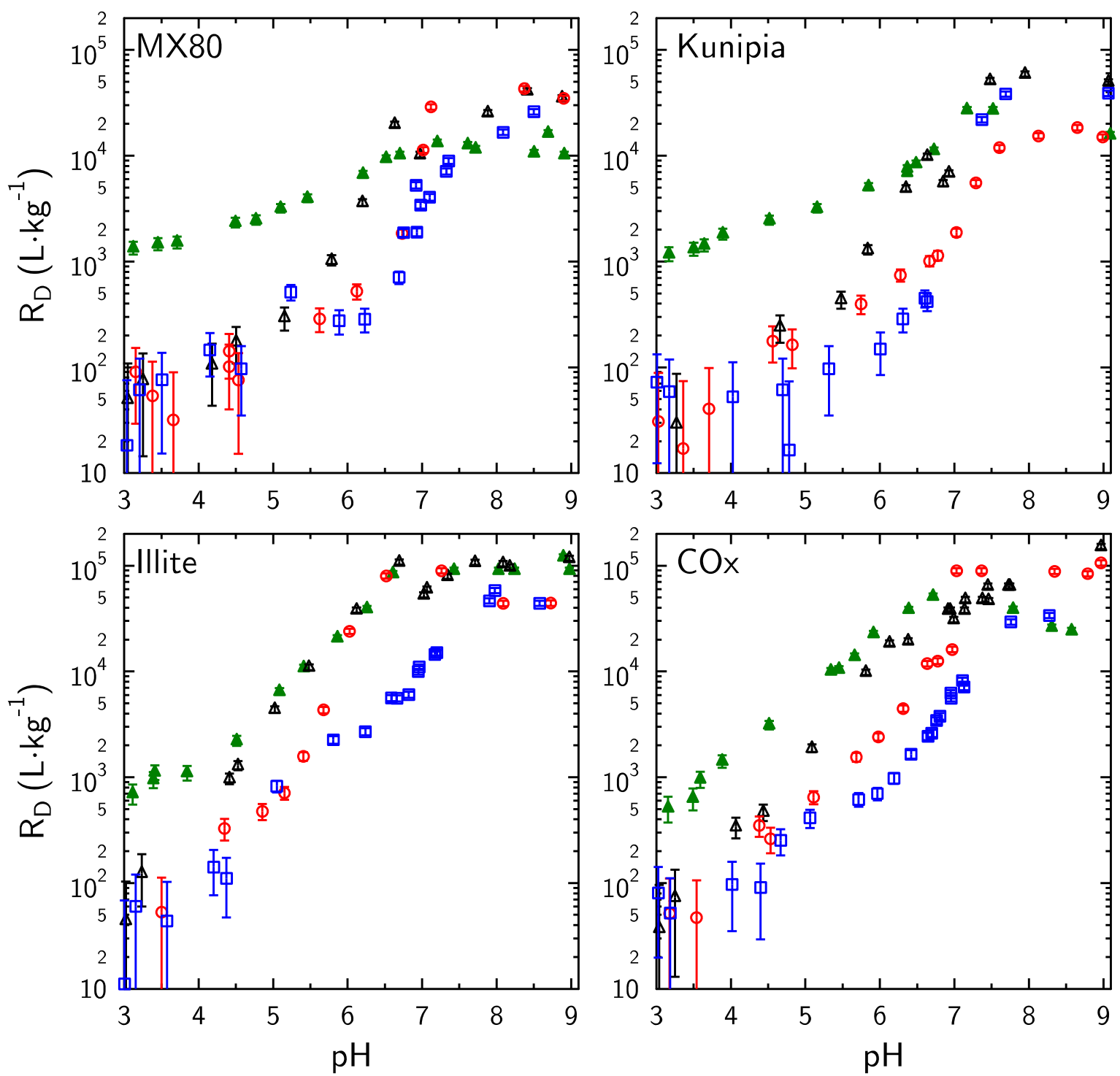


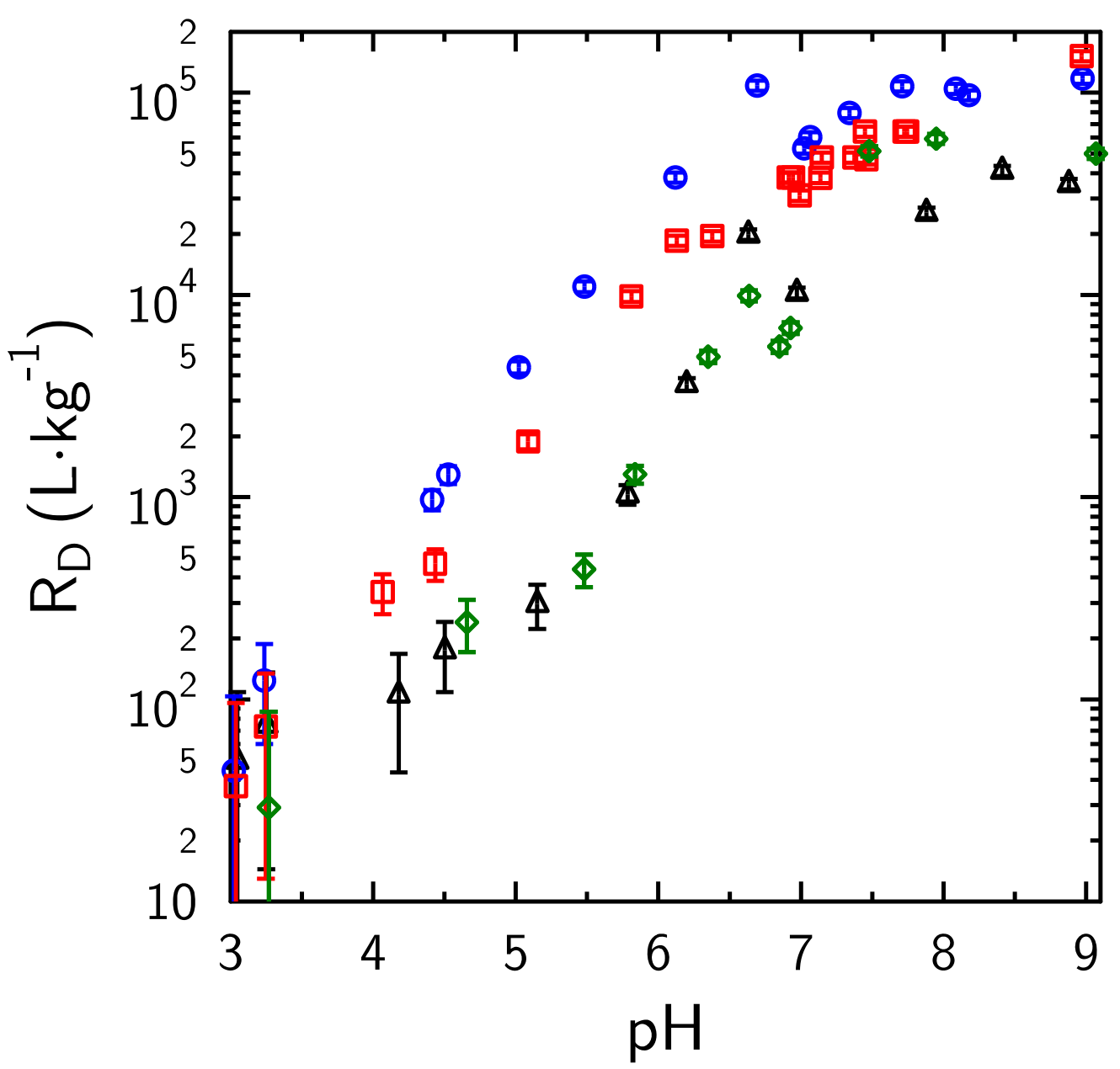



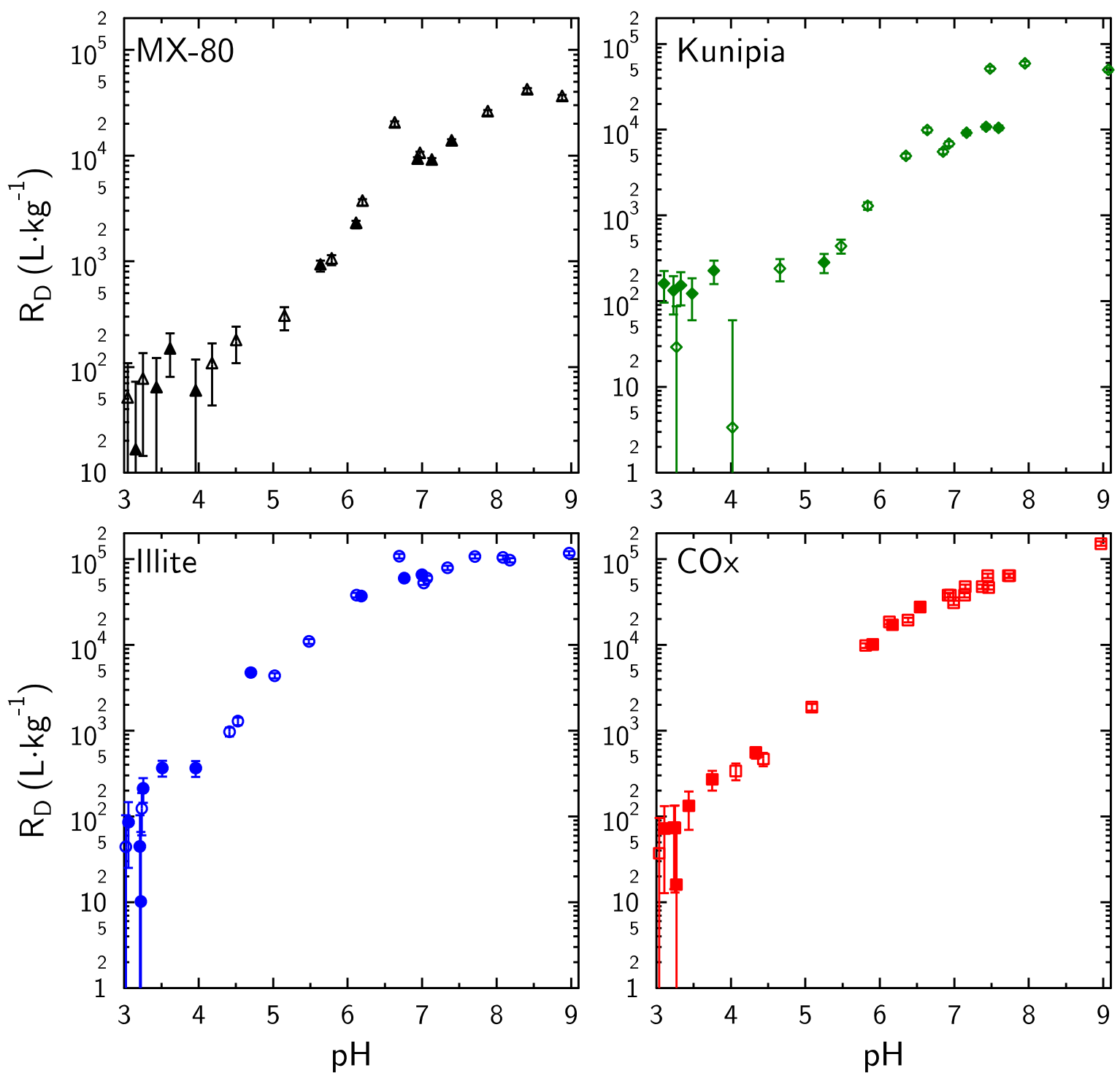
Figure 4

Click here to download Figure: Figure 4.pdf
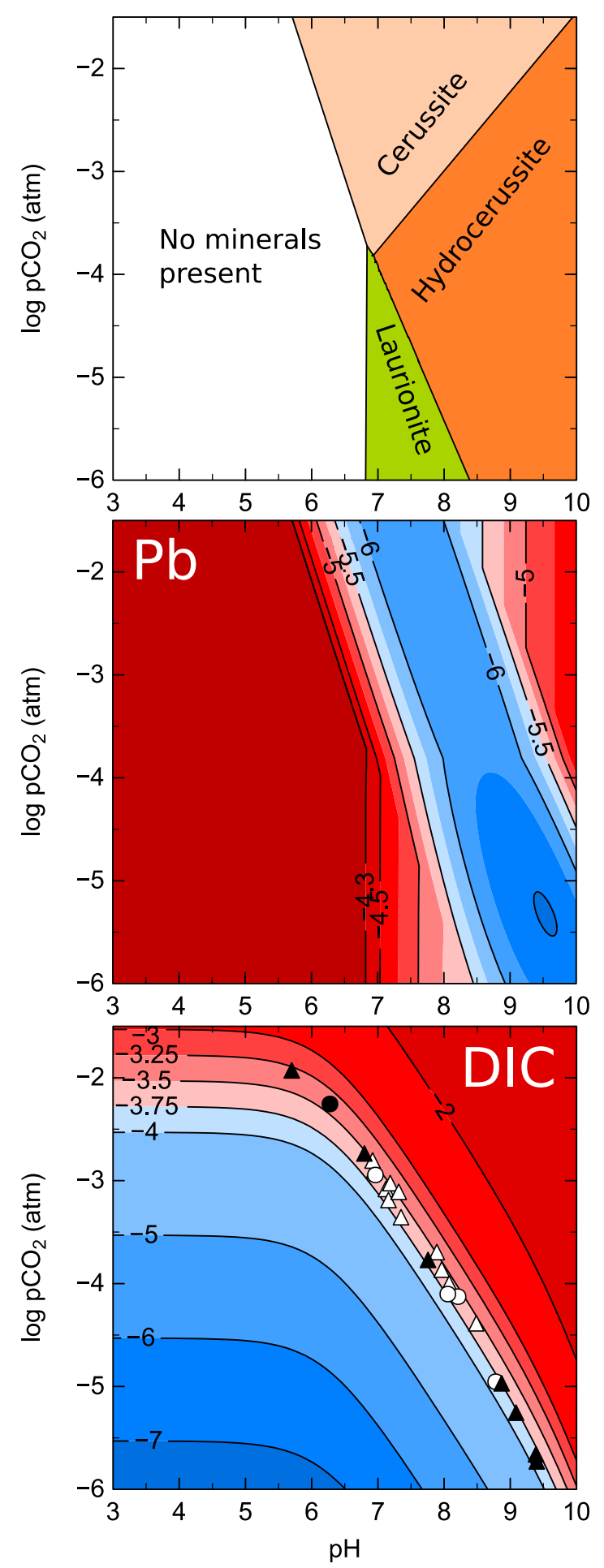

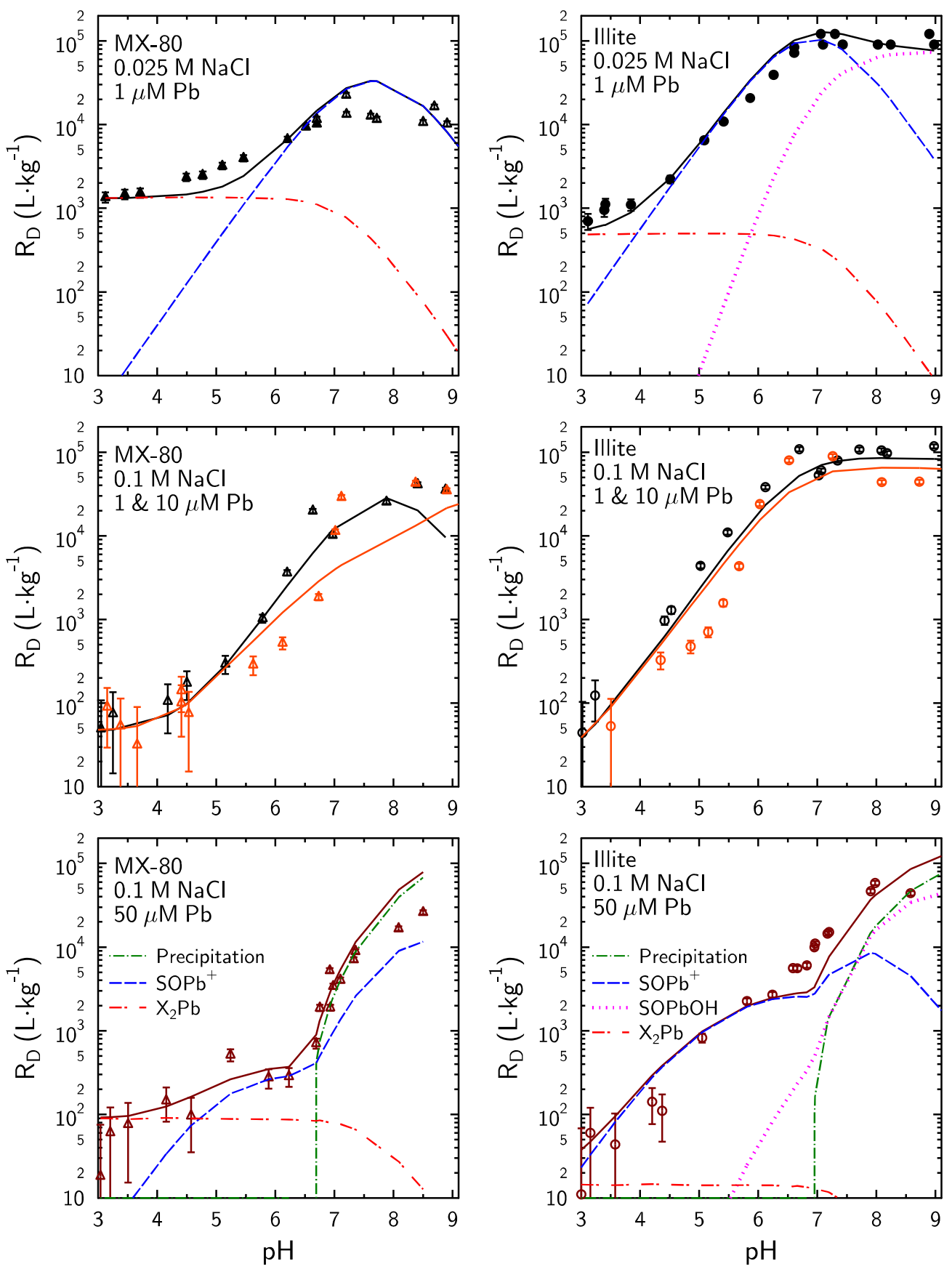

Can you print Figure 5 in one page, if it is possible? 

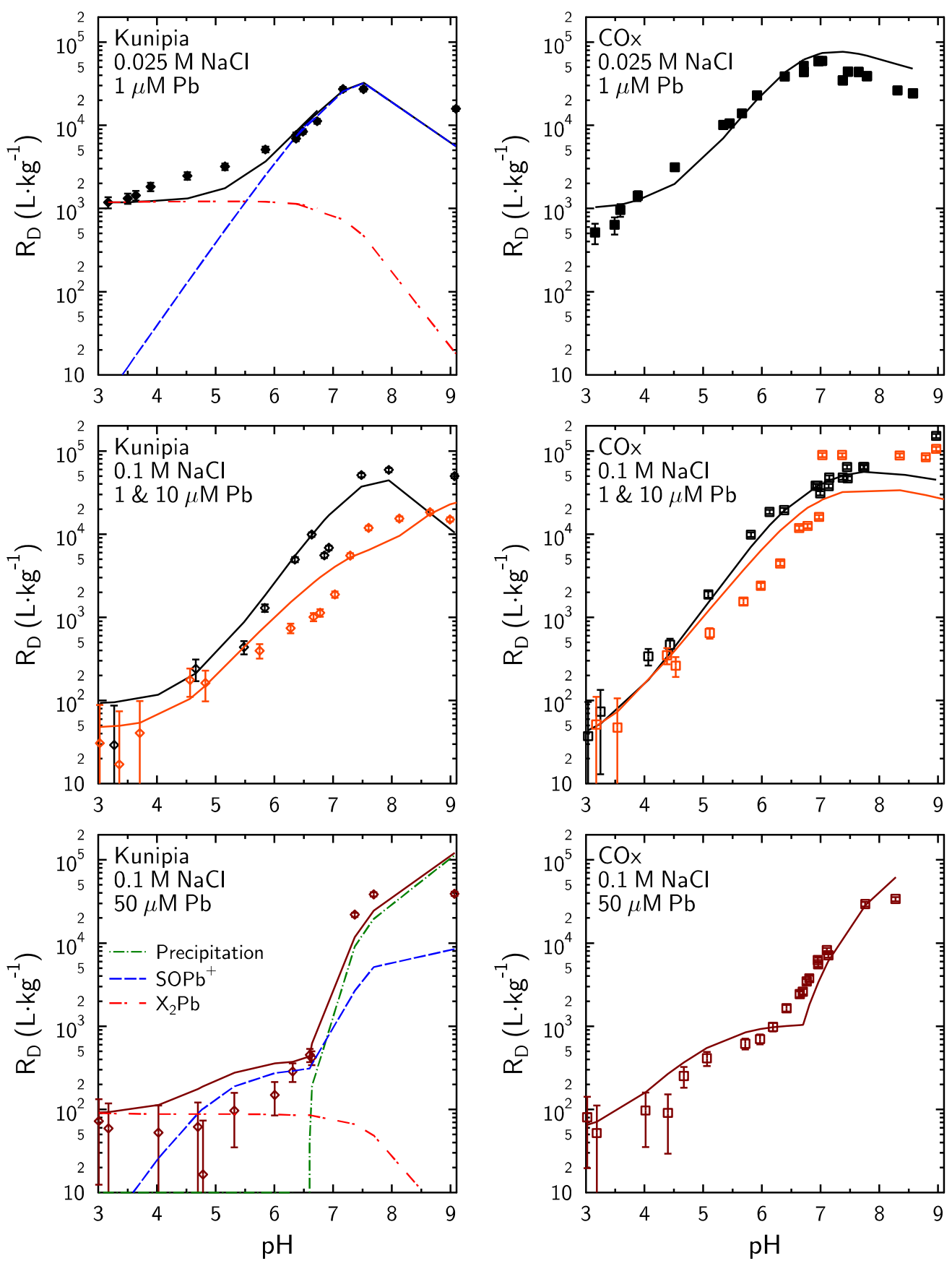

Can you print Figure 6 in one page, if it is possible? 

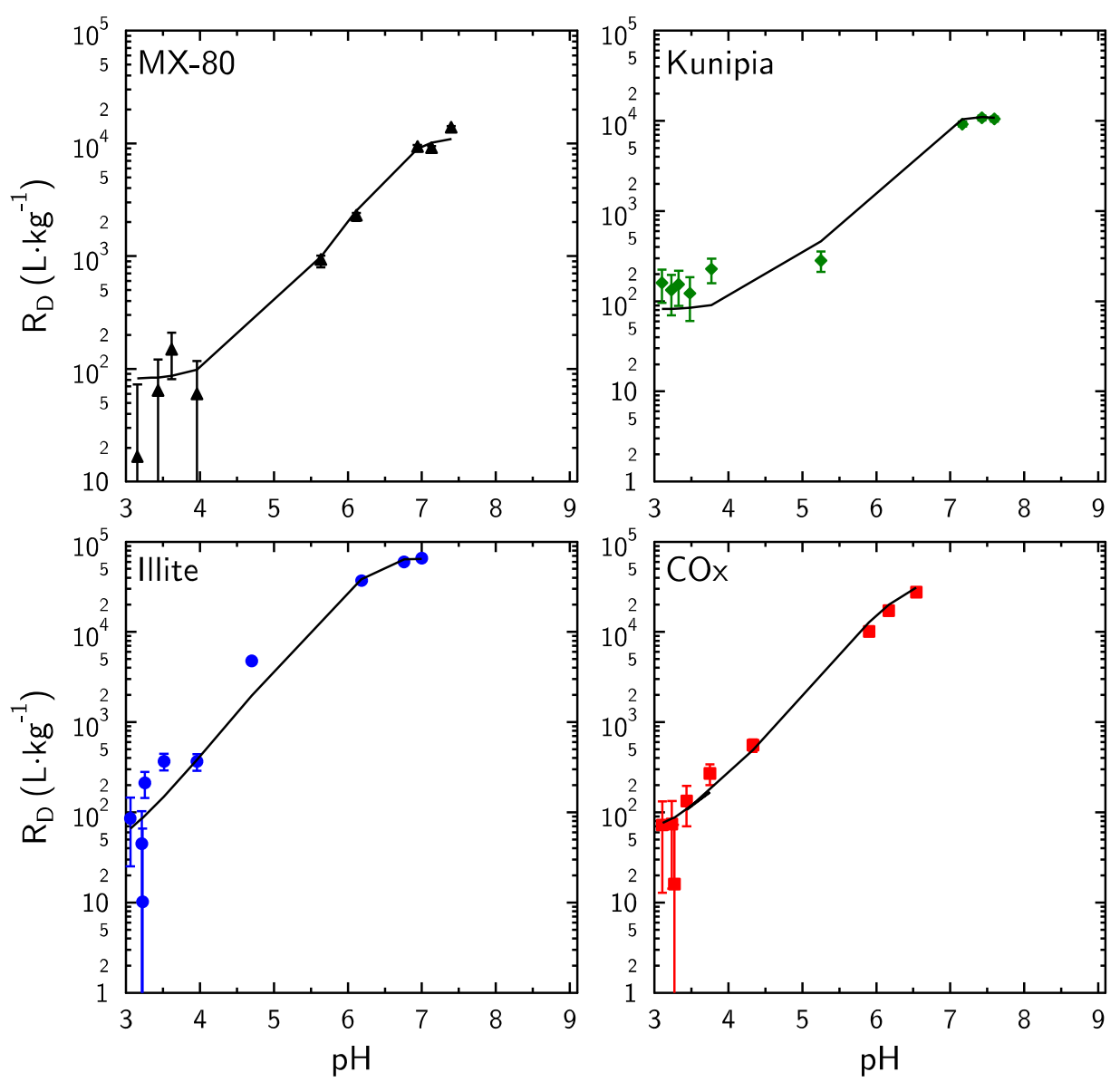

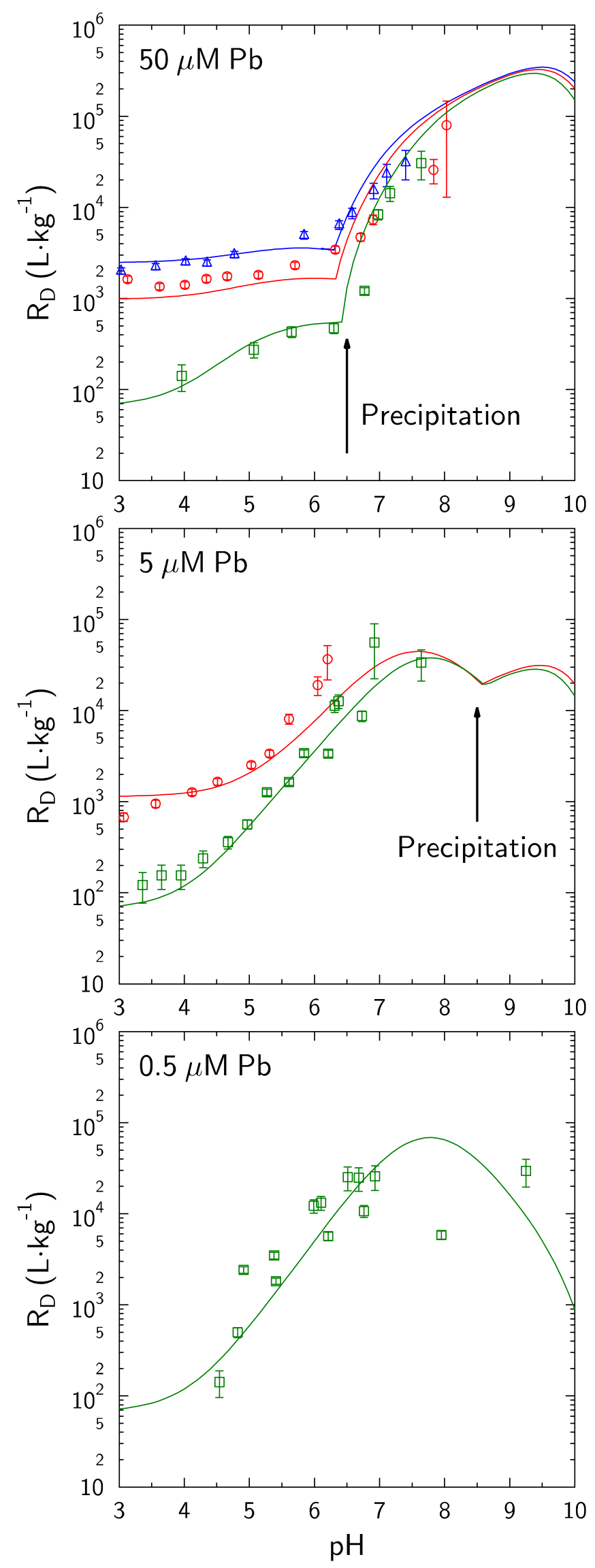
Figure 9

Click here to download Figure: Figure 9.pdf

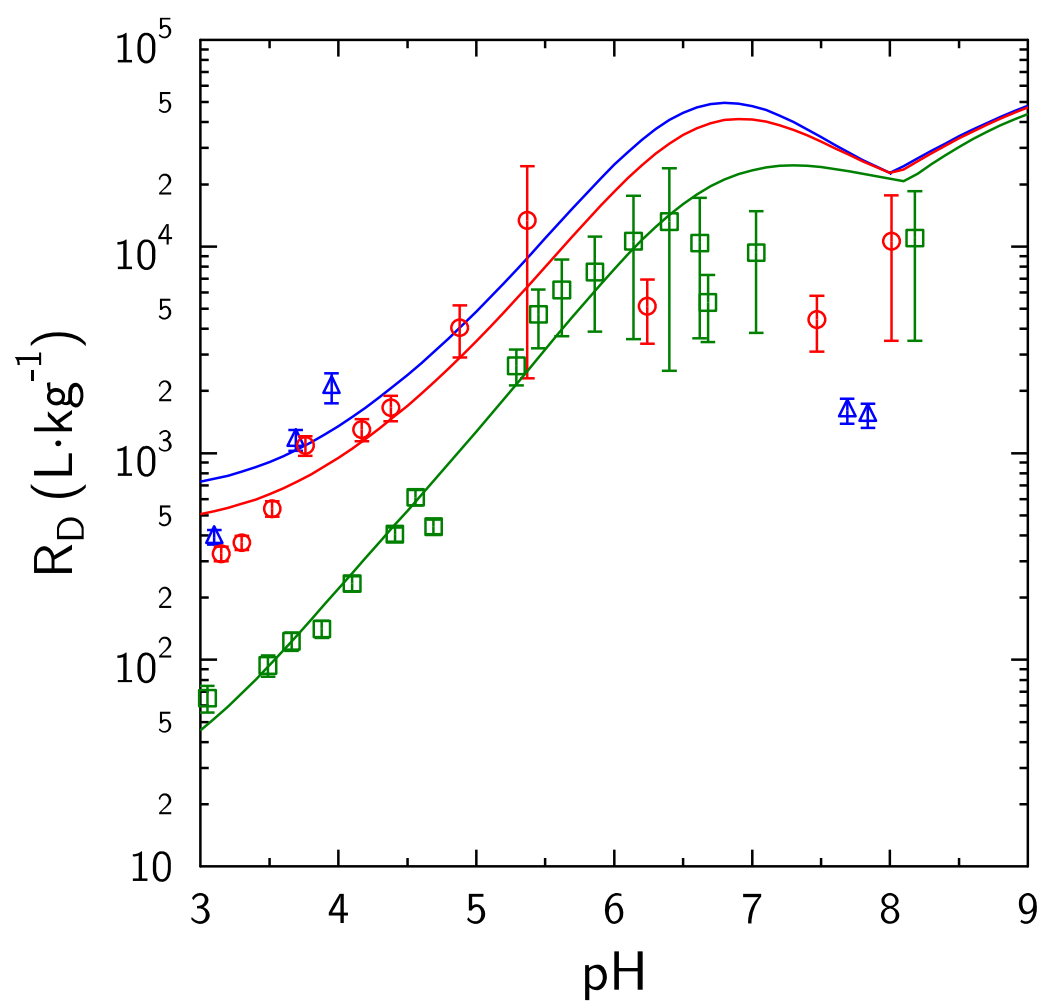


Figure 10

Click here to download Figure: Figure 10.pdf

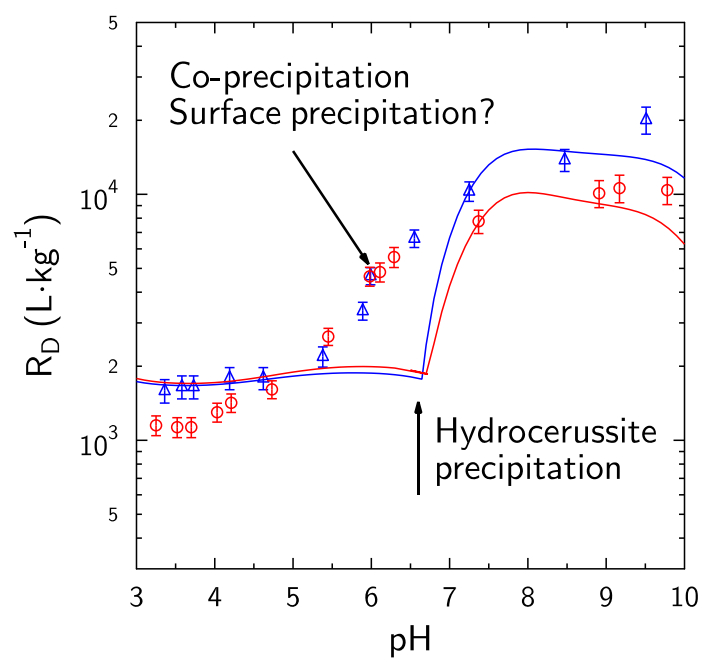




\begin{abstract}
Surface complexation models (SCMs) have been developed in the last decades to describe metal ion sorption to clay minerals and especially to montmorillonite. In principle, these models can provide relevant information about sorption of radionuclides to be used in performance assessment (PA) of radioactive waste disposal systems. However, these SCMs have been developed in parallel with the acquisition of distinct adsorption datasets, which are not always consistent with each other. The objective of this study was to compare new experimental adsorption results with literature data to understand these discrepancies and to propose a SCM approach that could be amenable to determine sorption related retention parameters necessary for PA calculations. This study focused on lead ( $\mathrm{Pb}$ ) adsorption on montmorillonite, illite and in a natural clay (Callovo Oxfordian) as case studies of a strongly sorbing radionuclide that undergoes a range of retention processes depending on the chemical conditions. The experiments showed that many experimental artifacts lead to misinterpretations of the processes underlying the measured retention values. These include $\mathrm{Pb}$ precipitation in the presence of carbonate in solution. The determination of SCM parameters to provide sorption related information for PA of clay minerals should rely on preliminary building of an adequate adsorption database, where adequate means that all experimental conditions are met to quantify surface complexation only.
\end{abstract}


Background dataset for online publication only
Click here to download Background dataset for online publication only: Supporting information-Revised2.pdf

Background dataset for online publication only
Click here to download Background dataset for online publication only: Supporting information-Revised2.pdf C

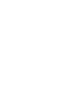

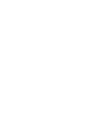

.

(1) 